\title{
Urban Elite Houses in the Song Dynasty
}

\author{
Ding Zhang
}

B. ARCH, South China University of Technology, 2015

\author{
A Thesis Presented to the Faculty \\ of the Department of Architectural History \\ of the School of Architecture \\ in Partial Fulfillment of the Requirement for the Degree \\ Master of Architecture History
}

School of Architecture University of Virginia

December 2017 


\section{Contents}

List of Illustrations

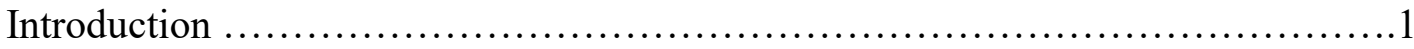

Chapter One Historical Background of the Song Dwellings ..................... 7

History background

Architectural background

Housing regulations in the Song

Chapter Two Elite Houses in Open Cities .................................20

Urbanization and the failure of the ward system

Distribution of elite houses in an open city

Chapter Three Urban Elite Houses .........................................27

The family ritual and elite houses

Fengshui for urban houses

The urban elite houses as images of mind

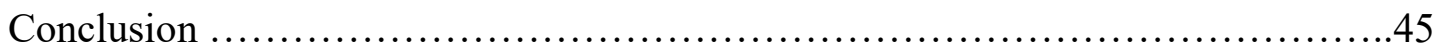

Bibliography....................................................... 47

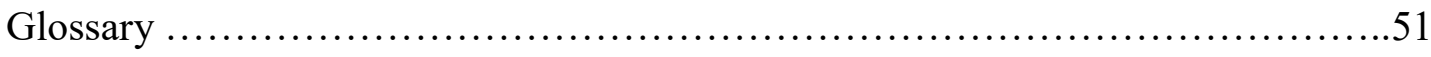

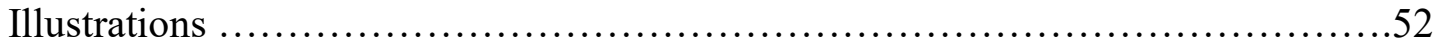




\section{List of Illustrations}

Fig. 1. The maps of the Northern and Southern Song. From:

https://ancientworld2009. wikispaces.com/5+Early+Chinese+Civ.

Fig. 2. Hualin Temple

Fig. 3, The dwelling of Xu. From: http://bbs.hqcr.com/article-107-1.html.

Fig. 4, Along the River During the Qingming Festival. From http://www.sohu.com/a/4401013_119389.

Fig. 5, Module in Yingzao Fashi. From Li Jie. Yingzao Fashi. 1103.

Fig. 6, Removable lattice window. From Ancient Chinese Painting Research Center of Zhejiang University. Song Hua Quan Ji, Vol. 1, Part 4 (Hangzhou: Zhejiang University Press, 2010), 94.

Fig. 7, Buildings for different status class.

a. 1. Detail of Shuige Naliang Tu. From: National Palace Museum in Taipei, http://www.npm.gov.tw/exhbition/jih0001/3.htm.

a. 2. Detail of Sijing Shanshui Tu. From Ancient Chinese Painting Research Center of Zhejiang University. Song Hua Quan Ji, Vol. 1, Part 4 (Hangzhou: Zhejiang University Press, 2010), 97.

a. 3. Detail of Along the River During the Qingming Festival. From Ancient Chinese Painting Research Center of Zhejiang University. Song Hua Quan Ji, Vol. 1, Part 2 (Hangzhou: Zhejiang University Press, 2010), 39.

b.1. City Gate. From Ancient Chinese Painting Research Center of Zhejiang University. Song Hua Quan Ji, Vol. 1, Part 2 (Hangzhou: Zhejiang University Press, 2010), 54.

b. 2. Wutou Gate. From Li Jie. Yingzao Fashi. 1103.

b. 3. Detail of $N v$ Xiangjing Tu. From: National Palace Museum in Taipei, https://www.npm.gov.tw/exh99/southernsong/img_04.html

Fig. 8. Lady Wenji's return to China: Wenji arriving home. From Museum of Fine Arts Boston, http://www.mfa.org/collections/object/lady-wenjis-return-to-china-wenjiarriving-home-29005.

Fig. 9, Type of Roof. From Liang Sicheng, Tuxiang Zhongguo Jianzhu Shi (Baihua Literature and Art Publishing House, 2001), 86.

Fig. 10. A three-story building used as restaurant in Along the River During the Qingming Festival. From Ancient Chinese Painting Research Center of Zhejiang University. Song Hua Quan Ji, Vol. 1, Part 2 (Hangzhou: Zhejiang University Press, 2010), 55. 
Fig. 11, Plan of Chang'an in the Tang dynasty. From:

http://www.ancientchina.org.uk/xian/.

Fig. 12, A ward in Chang'an. From Xinze Li, The Research of "Li Fang” System (PhD diss., Tianjin University, 2010), 35.

Fig. 13. The section of the street in the Tang Chang'an (above) and the Song Kaifeng (below). From Gangyi Tan, Liangsong Shiqi De Zhongguo Minju Yu Juzhu Xingtai [Chinese Vernacular Architecture and Settlements in Song Period](Nanjing: South East University Press, 2008), 203.

Fig. 14. Distribution of urban elite houses in early, mid, and later Tang Chang'an. From Yongshuai Zhang, "The Research on Residence in Chang'an in the Tang Dynasty" (Master Thesis, Shanxi Normal University, 2006), 36-8.

Fig. 15. a. Distribution of elite dwellings in Kaifeng (Hatched in dark grey), b. Land use in Kaifeng, according to literature resource. From Ye Deng, A Study on the Spatial Morphology of Dongjing City in North-Song Dynasty (Master thesis, Tsinghua University, 2004), 11, 86.

Fig. 16. A house plan in Book of Rites. From Chen Xiangdao, Book of Rites (ca. 106793).

Fig. 17, An illustration about about "Visting a friend," From Yang Fu, Illustration about Rites, 1228.

Fig. 18, Suichao Tu by Li Song. From http://www.cchicc.com/photo.php?id=96998.

Fig. 19, The map of Fuxie of Jiankang. From Local Chronicles of Jiankang in the years of Jingding

Fig. 20, A new drawing of fuxie of Jiankang according to Local Chronicles of Jiankang in the years of Jingding. From Lin Yuan, Songdai Chengshi Xingtai He Guanshu Zhidu Yanjiu [City Form and Administrative Architecture in the Song Dynasty] (Beijing: China Architecture and Building Press, 2013), 119.

Fig. 21, The fuxie part in the engraved Map of Pingjiang

Fig. 22, Tongyin Wanyue Tu. From Ancient Chinese Painting Research Center of Zhejiang University. Song Hua Quan Ji, Vol. 1, Part 7 (Hangzhou: Zhejiang University Press, 2010), 17.

Fig. 23, An imaging plan of Fuzheng Garden. From Dongge Guo, “The Features Research of Luoyang Private Garden Title in the Northern Song Dynasty" (Master Thesis, Henan Agriculture University, 2013), 22.

Fig. 24, A copy of Li Gonglin's Picture of Gathering in West Garden. From https://zhuanlan.zhihu.com/incense/20006536. 
Fig. 25, Imperial Garden, Jingming Pool, in Competition on the Jinming Pool. From Tianjin Museum Institution, http://www.tjbwg.com/product_2387.html.

Chart. 1. Comparison of housing regulations of the Tang, Song and Ming dynasty. 
Introduction

From the late 10th century to the 13 th century, Chinese society underwent a radical transformation. The Song dynasty (960-1279), ruled by the Han ethnic group, was one of the regimes that appeared in China during that time. The Song dynasty was divided into two periods: the Northern Song (960-1127) whose capital was in a northern city Kaifeng, and the Southern Song (1127-1279) who retreated its capital to a southern city Hangzhou because of the invasion of Jin. (fig. 1) Although the Song, comparing to the Han and Tang Dynasties, had a weaker military power and smaller empire, the Song had an economic revolution and a Chinese Renaissance, which led to an enlightened and liberal intellectual life in China. The rapid growth, broad diversification of trade and population increase and concentration in cities fostered a progressive urbanization. The breakdown of the "ward system" and the proliferation of trading posts and periodic markets shaped a new urban structure, which was one of the most dramatic and major changes in Chinese urban history.

Furthermore, as aristocratic families collapsed in the years of turmoil before the Song, scholar-officials formed the new elite class in the Song society. They fostered the revival of Confucianism, which represented a new philosophical emphasis on the ideal of universal reasoning and promoted curiosity in every realm of knowledge. Chen Yinke (1890-1969), a famous contemporary Chinese historian, claimed that Chinese culture which evolved during thousands of years, crested in the Song dynasty. ${ }^{1}$ Yan Fu (18541921), a Qing scholar and translator, claimed that phenomena in contemporary China were mostly inherited from the Song dynasty, which is the most important period if

\footnotetext{
${ }^{1}$ Yinke Chen, "Preface of Songshi Zhiguanzhi Kaozheng" in Jinming Guan Conggao vol. 2 (SDX Joint Publishing Company, 2001), 245.
} 
studying the transformation in humanity, politics, traditions. ${ }^{2}$ In this socioeconomic and cultural background, domestic architecture evolved in distinctive ways.

Domestic architecture usually has a weaker voice than religious architecture and imperial structures. Palaces, as a symbol of imperial power, usually has many literary records and maps. Religious architecture, maintained by religious followers or communities, usually lasts longer, because it is not auspicious to demolish temples in traditional thought. However, Houses, as private properties, were easily changed and were seldom recorded. The surviving Song above-ground structures are usually wooden temples and brick pagodas. (fig. 2) The Dwelling of Xu Yu (a son-in-law of the Song Emperor Taizong) in Chaozhou probably is one of the complete urban elite house that relates to the Song dynasty. (fig. 3) Although the stone base of this dwelling could date from the Song, the wooden structures are usually identified as Ming or Qing structures. Because of the lack of surviving structures in early dynasties, studies of domestic architecture mainly focuses on the Ming, Qing, and the Republican period. Research on earlier domestic buildings are usually based on literary sources and archaeological evidence, such as mural paintings and offerings. ${ }^{3}$ For the study of the Song architecture, literary materials and paintings were the major resources. As the printing techniques were developed and popularized in the Song, many more books were printed in this period than in earlier dynasties, and therefore the surviving archives from the Song were more than earlier dynasties, even if only few words refer to architecture. Moreover, with the development of the landscape painting and folk painting, architecture was a popular

\footnotetext{
${ }^{2}$ Fu Yan, "Zhi Xiong Chunru Xin" [Letter to Xiong Chunru], Xueheng 13 (1926).

${ }^{3}$ Gangyi Tan, Liangsong Shiqi De Zhongguo Minju Yu Juzhu Xingtai [Chinese Vernacular Architecture and Settlements in Song Period] (Nanjing: South East University Press, 2008), 4.
} 
element in the Song paintings. In the meantime, thanks to the rise of Jie Painting in the Song, the building depicted in these Song paintings usually have a relatively precise dimension and details.

The Song is a significant period of traditional Chinese architecture. Yingzao Fashi provided a large amount of architectural visual images and literature in a professional perspective, which became a primary material to study technics, structure, decoration of the Song architecture. The surviving wooden temples and pagodas in the Song are also popular topics. The Song is also famous for its open urban layouts. Many scholars focus on the history of the city and planning, taking Kaifeng (the capital of Northern Song), and Lin'an (the capital of the Southern Song) as examples, such as Kaifeng during the Song period by Japanese scholar Kazuo Kubota and Cities of Aristocrats and Bureaucrats: The Development of Medieval Chinese Cities by Chye Kiang Heng.

However, the Song domestic architecture, which usually appeared as a small section in a general history, attracts little attention. History of Architecture in the South Song, a recent book of Guo Daiheng, who is an expert in the Song architecture, provides an overview of architecture in the Southern Song, including topics in cities, palaces, imperial tombs, religious architecture, gardens, educational architecture, domestic architecture, commercial and entertaining architecture, bridges, techniques. The domestic architecture section includes village planning, dwellings in cities and villages, a dwelling in literature and dwellings of minorities in Southwest China. ${ }^{4}$ Given the lack of materials, "the dwellings in cities" section is only five pages including illustrations. In this section, Guo interprets urban houses depicted in two city maps and five paintings, and mainly

\footnotetext{
${ }^{4}$ Daiheng Guo, Nansong Jianzhu Shi [Architecture in the Southern Song] (Shanghai: Shanghai Ancient Works Publishing House, 2014), 329-47.
} 
focuses on the house layout. She argues that the urban house in the Song China was usually courtyard house, in which the main entrance and main halls are located on axis. These buildings use brackets, moon beams and tiled roofs. Gardens were usually built behind the house. ${ }^{5}$

In Recent years, researchers on Chinese Architecture gradually turn their attention from the palace or religious architecture to vernacular architecture such as dwellings, and from architectural techniques, layout, and decoration to their cultural meaning. Tan Yigang's Chinese Vernacular Architecture and Settlements in Song Period discusses dwellings in term of its social backgrounds. This book focuses on all domestic architecture in the Song, Liao, and Jin regime of that time. Tan concludes that the Chinese house became mature in the Song dynasty. The Song lifestyle was involved in a tightly woven social fabric because of the economic and technical prosperity. ${ }^{6}$ This book, like many other publications, does not discuss dwellings in city and countryside separately. The differences between country houses and urban houses and how the urban environment influenced the development of urban houses were seldom analyzed.

Bao Weimin, a famous scholar who specialized in the Song, researched on the urban culture during the Song. His article, "New Discussion of City Culture in the Song Dynasty" provides an analysis of the elite culture, citizen culture and their relations in Song cities. Bao argues that the cultural center was transferred from rural areas to urban areas in the Song dynasty. He asserts that urban culture was dominated by the elite. ${ }^{7}$

\footnotetext{
${ }^{5}$ Daiheng Guo, Nansong Jianzhu Shi [Architecture in the Southern Song] (Shanghai: Shanghai Ancient Works Publishing House, 2014), 340.

${ }^{6}$ Gangyi Tan, Liangsong Shiqi De Zhongguo Minju Yu Juzhu Xingtai [Chinese Vernacular Architecture and Settlements in Song Period] (Nanjing: South East University Press, 2008), 282-285.

${ }^{7}$ Weimin Bao, "Liangsong Chengshi Wenhua Xinlun" [New Discussions in City Culture in the Song Dynasty] in Journal of Literature, History and Philosophy 5 (2012), 107.
} 
Former studies focusing on the traditional urban house are scarce. This thesis focuses on urban domestic architectures in the Song dynasty. Geographically, this paper only focuses on the area ruled by the Song Court, which is smaller than the area of the Tang dynasty. This area was governed by ethnic Han, dominated by the ethnic Han culture. Reigns of Liao and Jin are not included in the discussion, because they have different social backgrounds, and some have more local features in building, such as nomadic style.

Moreover, this thesis focuses solely on the urban house, and does not include the settlements in rural area. Urban houses, far away from fields, were built side by side in the city with a high population density. Cities were political and economic centers, so the urban houses were usually more sensitive to new techniques, new fashions, and policies than country houses. The swift in city layout made urban houses more involved in a complicated physical and social environment than ever before.

Furthermore, this thesis focuses on dwellings of elites. The Song elite in this thesis means the newly emerging class of scholar-officials. They may be born to humble families, scholarly families and even the imperial clan. They were educated in Confucian doctrine, and became officials through the Examination system. They usually have brilliant intelligence and outstanding tastes in houses. On the other hand, literary sources, usually written by scholars, recorded much more information about elite houses than common people's house.

The elite house, because it was a direct outgrowth of the political and social fabric of the Song dynasty, must thus be understood within the context of that world. Chapter 1 focus on the political and economic climate in the Song dynasty, and offers a brief 
overview of Song architecture. Chapter 2 talks about the collapse of the ward system and the change in the distribution of the elite houses. Chapter 3 uses various materials to analyze urban elite houses and how they were used. This thesis will try to demonstrate the urban elite houses in its socioeconomic backgrounds and its physical environment the open city. By examining the literary sources and visual materials, like maps and paintings, this thesis explores the domestic ideal of the Song elites. The elites were given the privilege to build grand urban houses. These urban houses symbolized the elites' social status by carrying their daily routine of the elite group and the distinctive taste of their own. 
Chapter 1 Backgrounds of the urban elite house in the Song

History Background

From the late Tang to the early Song, China witnessed years of turmoil and division. During this period, military governors in the Tang led a rebellion and built their regimes. At the same time, the central plain of China was threatened by the nomadic intruders from the north. In 960, Zhao Kuangyin (927-77), a general of one kingdom, usurped the throne and founded the Song empire. In the following years, he annexed some other military forces and territories to his central government and set his capital at Kaifeng. Learning from his experience, Zhao Kuangyin, usually called Emperor Taizu, understood the powerful generals' threaten to his sovereignty. Therefore, he curbed the political power of military commanders and created a new governmental structure which was composed of scholar-officials selected through the Examination system. He persuaded the generals to "possess more money, cloth, land, and houses which could be inherited by descendants, and entertain themselves with singing and dancing in the limited lifetime" rather than to retain military power. ${ }^{8}$ The principle of strengthening civil authority over military authority became the creed of all emperors of the Song dynasty.

Liao, Western Xia, and Jin regimes in northern and western China with overwhelming military skills continued to battle with the Song, although Emperor Taizu united the area encompassing the Central Plains of China to the south of the Yangzi River. The Song lost its territory to the north of the Huai River when a northern regime Jin intruded. The Song court signed the document which claimed itself as a vassal of the Jin and paid an annual tribute to the Jin regime in 1142. The Song court retreated to Li' an

\footnotetext{
${ }^{8}$ Toqto'a, "Records of Carriages and Apparel," in History of Song (1343).
} 
(now Hangzhou) and finally built its new capital there. Later in 1271, the Song fell to the Mongolian troops, and Khubilai (1215-94) proclaimed a new dynasty which was known as Yuan. Historically, the Song before 1127, whose capital is Kaifeng, is called the Northern Song. The Song after 1127, whose capital is Li'an, is called the Southern Song.

The social structure changed considerably from the Tang to the Song dynasty. Qian $\mathrm{Mu}$, a famous historian of twentieth-century China, believed that the most significant social shift in China occurred in the Song period. He claimed that before the Song, Chinese society was similar to an aristocratic society, while after the Song, China became a civilian society because high-ranking officials were usually born to civilian families. ${ }^{9}$ Aristocratic families, who were elites with great political power during the Tang period, fell in the turmoil before the Song. To avoid divisions caused by aristocratic families and royal relatives, the Song rulers centralized military power in their own hands. Military commanders relinquished their military authority and served as high-ranking officials. Members of the royal clan could not have the privilege of achieving powerful positions without passing the Examination. ${ }^{10}$

A newly emerging class of scholar-officials were pushed to the stage and became the new managers in the political structure. These officials were selected through a nationwide examination system, which was open to people either from a literary family or a humble family. During the Jin dynasty (265-420), "no officials from humble families can reach high rank, while no officials from aristocracy families are in low rank."11

\footnotetext{
${ }^{9} \mathrm{Mu}$ Qian, The Outline of Chinese History (Commercial Press, 2011), 233.

${ }^{10}$ Zhaoquan He, Nansong Mingren Yu Lin'an [Celebrities and Lin'an in the Southern Song] (Hangzhou Press, 2010), 256.

${ }^{11}$ Xuanling Fang, "Biography of Liu Yi” in Book of Jin, vol. 45 (646-648).
} 
Although the Examination system was created in the Sui dynasty (581-618), educational resources were concentrated in aristocratic families, and the examination was not the main method of elite selection. It was in the Song that people from humble families could really make high-ranking officials. Of the seventy-one prime ministers in the Northern Song, except the first four of them who made a great contribution to the establishment of the Song, only three of the seventy-one prime ministers were not selected by the Examination system. ${ }^{12}$ To recruit a large number of people in civil service, the Song court widely promoted education and the Examination system which based on Confucian classics.

The scholar-officials, once presented with education and political opportunities, proved to be competitive and dynamic. ${ }^{13}$ Confucianism, as well as Buddhism, and Daoism developed through their efforts during the Song period. Scholars reinterpreted the Confucian classics to explore universal principles of the value system that the society needed. Scholars were also inspired by the approaches of spiritual cultivation in Daoism and Buddhism in order to develop analyses on a wide range of subjects such as cosmos, humanity and practice. ${ }^{14}$ As a result, this built a new philosophy system $L i X u e$, which is also called New-Confucianism by foreign researchers. New-Confucianism was not only a new philosophy system but also social and political thought which helped emperors to strengthen their sovereignty. Emperor Xiaozong (1127-94) proposed to "use Buddhism to

\footnotetext{
${ }^{12}$ Hongjie Zhang, Zhongguo Guomin Xing Yanbian Licheng [The transformation of Chinese personality] (Hunan Art Press, 2016), 91.

${ }^{13}$ Wen Fong, Beyond Representation: Chinese Painting and Calligraphy, 8th-14th Century (Metropolitan Museum of Art, 1992), 120.

${ }^{14}$ Lai Chen, Song Ming Lixue [New-Confucianism in the Song and Ming dynasty], East China Normal University Press, 2004, 1-15.
} 
cultivate temperament, use Daoism to improve well-being, and use Confucianism to govern the country."15

The Song dynasty also presented a remarkable achievement in technology. New Confucianism raised the awareness of skepticism and reformation. Song scholars recruited through examinations were encouraged to investigate nature, conduct experiments, and invent new technologies in agriculture, textile and ceramic production, iron refining, shipbuilding, armaments manufacture, mathematics, medical science, and many other fields. Especially, the movable type printing triggered the quick and mass production of books, which made a great contribution to the rapid spread and affordability of information and knowledge. In 1005, a Song scholar Xing Bing (9321010) said that, "nowadays, woodblocks for printing various books are so abundant that scholars and humble families can have books." ${ }^{16}$ A Yuan scholar Wu Cheng (1249-1333) highly praised the Song printing technique that, "we do not need to acquire knowledge by ear like people before the Han, and by copying books like people in the Tang; we are so lucky that it is much easier for us to read." ${ }^{\prime 17}$ In the meantime, the popularity of printed books, which could contain domesticating knowledge written by scholars or scripts written for common people, contributed to the interaction between classes.

The Song dynasty is also an era featured unprecedented economic prosperity. As the silk road was blocked in the mid-Tang, the Song court actively promoted trading activities throughout the nation, and opened up the marine silk road through some coastal cities. In the Southern Song, the annual tribute to the Jin and later the Mongolian placed a

\footnotetext{
${ }^{15}$ Shen Zhao, "Yuandao Bian" in Quan Song Wen vol. 236 (1181).

${ }^{16} \mathrm{Li}$ Tao, Xu Zizhi Tongjian Changbian vol. 60 [Extended Continuation to Zizhi Tongjian] (1183).

${ }^{17}$ Wu Cheng, "Zeng Yu Shu Ren Yang Liangfu Xu” in Works of Wu Cheng, vol. 19 (ca. 1249-1333).
} 
heavy financial burden for the Song court, and therefore economic development became a more urgent issue. Although the Song occupied a smaller area than other dynasties, the annual tax revenue in the Song was much higher than any other dynasties in ancient China. ${ }^{18}$ The mid-late Northern Song had an average annual tax revenue about $80,000,000$ to $90,000,000$ ounces of silver, and the revenue in the Southern Song once reached up to $160,000,000$ ounces of silver. The Ming dynasty' annual revenue reached its crest after the tax reform in 1600 , which was only 4,000,000 ounces of silver. It was only at the end of the Qing dynasty (1636-1912) that its tax revenue could compete with that of the Song dynasty. However, by the end of Qing dynasty, it has tripled in population compared to the Song, and more than doubled in the territorial area compared to the Song. ${ }^{19}$ For the attitude towards commerce, the traditional thought of stressing agriculture and despising commerce was challenged in the Song. In early-mid Tang, people from artisan and merchant families were not allowed to attend the Examination. However, the social status of the merchant in the Song rose. The Song court encouraged trade, and it was common for officials to get involved in trade.

As a rapidly expanding population and increasing prosperity due to the growth in trade, a large number of new towns sprung up as economic centers surrounding big cities. A city in the Song period was not purely a political center or military center as before, but also a commercial center. The closed ward-system cannot satisfy the increasing demand for trade. Restrictions on commercial activities in space and time were loosened and eventually abandoned. The streets were filled with various commercial and entertainment

\footnotetext{
${ }^{18}$ Xia Qi, Zhongguo Jingji Tongshi: Songdai Jingji Juan [History of Chinese Economy: the Song dynasty] (Economy Daily Press, 1999), 25-40.

${ }^{19}$ Ying Wang, The Amalgamation Between The Aesthetics Culture and Daily Life in Song Dynasty (Master Thesis, Lanzhou University, 2008), 15.
} 
buildings which were open day and night. This new open urban structure formed gradually and provided considerable freedom of commercial activities and daily life as a consequence. The political, ideological, philosophical, cultural, literary, artistic, technological, and scientific achievements, combined with powerful economic forces that reconfigured daily life define our understanding of the Song as a transformative dynasty. ${ }^{20}$

\section{Architectural Background}

The strong economy, better-educated society, developing technology, and new philosophies shaped the distinctive attributes of Song architecture. Urban planning, wooden architecture, brick architecture, architectural decorations and gardens all developed rapidly during the Song.

Compared with the splendid architecture in a larger scale in the Tang dynasty, buildings and their attached gardens of the royal and private families of the Song dynasty evolved "a style even more artistic, exquisite, elegant, poetic, and self-conscious." ${ }^{21}$ Due to the elites' active involvement in every respects, architecture was not only built for its function and the owner's aesthetic pursuit, but also bore a name or inscriptions expressing the owner's political ambition and philosophical thoughts.

Varied new types of architecture appeared in the Song dynasty. Due to the demand for commercial space, a new open urban layout replaced the closed ward system. Homes, which included a store along the streets and living space in the back, or a store downstairs

\footnotetext{
${ }^{20}$ Dieter Kuhn, The Age of Confucian Rule: The Song Transformation of China (Belknap Press of Harvard University Press, 2011), 1.

${ }^{21}$ Daiheng Guo, "The Liao, Song, Xi Xia and Jin" in Chinese Architecture, ed. Nancy S. Steinhardt (Yale University Press, 2002), 136.
} 
and living space upstairs, sprung up. Multi-story commercial buildings were widely used as restaurants and hotels. The emphasis on education in the Song gave rise to a large number of schools and academies sponsored by the government or individuals both in cities and the countryside. Eventful civic life led to various entertainment buildings in cities, such as a main entertainment venue, called wazi, which was a large complex including theaters, restaurants, casinos and shops. ${ }^{22}$ One shelter in a wazi in Kaifeng could serve more than 1000 people. $^{23}$

A Song masterpiece Along the River During the Qingming Festival depicts the view from suburban to urban areas of Kaifeng. (fig. 4) In the outer suburbs, there were some farmhouses, only one of which was covered with a tile roof, while others featured a thatched roof. In the inner suburbs, more buildings and cargo ships appeared. Restaurants, teahouses, and workshops were built along the street. Vendors crowded on each side of a bridge. Most buildings were one-story covered with a tile roof. Across a city gate was the urban area. More two-story or three-story buildings, usually large restaurants and hotels, were crowded with people. The streets were bustling with vendors, pedestrian, sedans, and freighters. In this painting, commercial activities were all around the urban and suburban areas. From suburban to urban areas, population and building density increased, and structures became more delicate and well-organized. Exquisite urban houses were surrounded by commercial buildings along the busy streets.

Architectural techniques also made a significant achievement in the Song. Modular construction was widely applied in the Song and was recorded in Yingzao Fashi. The

\footnotetext{
${ }^{22}$ Yuanlao Meng, Dongjing Meng Hua Lu [The Eastern Capital: A Dream of Splendor] (ca. 1090 - 1150), vol. 7.

${ }^{23}$ Ibid.
} 
dimensions of each wooden structural components were determined a basic unit cai. (fig. 5) Architects would apply a large cai to build a larger wooden component. Yingzao Fashi (Treatise on Architectural Methods or State Building Standards), which was published by the Song court, is the earliest official architecture manual in Chinese history. About one hundred years after the establishment of the Song emperor, the society was relatively stable and developed rapidly. Luxurious aesthetics on buildings were revived, and corruption became a big issue in architectural construction. Therefore, the Song court decided to enact a law to avoid corruption and abuse of materials. Yingzao Fashi, finished in 1100, was written by a scholar-official Li Jie (1035-1110) who had much experience in construction. This book incorporated building rules and regulations, accounting information, standards for materials used in construction, and the classification of various crafts. It regulated the measurement of major wooden components by proportion in order to control material usage. Li Jie also made a glossary of construction terms in order to formulate a national policy. This book, which was republished continuously in the Southern Song, Yuan, Ming and Qing dynasties, has a significant influence on later Chinese architecture. ${ }^{24}$

Although this manual, as a law, was only used to regulate structures built by the government, such as administrative offices and city gates, it is still a significant reference to understand the structure and decoration of the Song private houses. Nevertheless, the knowledge in this book was summarized from the experience of contemporary artisans, so that it reveals some popular models or decoration patterns in the Song buildings. However, for the purpose of controlling construction expenses, Yingzao Fashi focuses on

\footnotetext{
${ }^{24}$ Daiheng Guo, Nansong Jianzhu Shi [Architecture in the Southern Song] (Shanghai: Shanghai Ancient Works Publishing House, 2014), 10.
} 
the most typical type of individual buildings, and does not cover information on landscape architecture like pavilions and the arrangement of buildings.

The type and style of wooden decoration in the Song was also a great achievement. More wooden surfaces, especially doors, windows, and ceilings, were heavily decorated, and their design quality increased significantly; for example, a new wooden lattice window frequently appeared in the painting of the Southern Song. These windows served as walls, which could be easily removed when it was too hot in the summer, so that a hall could be transformed into a pavilion. (fig. 6)

\section{Housing Regulations in the Song}

In addition to Yingzhao Fashi, Regulations of Housing is another official set of rules on housing. In imperial China, the court imposed rules to regulate daily life, including clothes, buildings, and vehicle used by different social classes to stress the idea of hierarchy. The imperial family, officials and common people were clearly identified by what they used. According to owners' social status, the housing regulations usually covered building forms, the complex's layout and decorations. Dwellings were not only space for living but also a manifestation of social status. The Song regulations, referring to regulations in earlier dynasties, were formulated in the light of the situation at the time. Therefore, these regulations indicated the unique housing condition during the Song. The official housing regulations classified houses into entitled royal family members, officials of different ranks, and common people. Officials' houses were further classified by numbered official ranks. ${ }^{25}$

\footnotetext{
${ }^{25}$ Official ranks was denoted by salary. Numbered from rank one to nine, officials were separated into Upper, Middle and Lower classes, each composed of three ranks.
} 
Regulations on Housing in the Song dynasty clearly distinguished different designations of the house for different people: the houses of a few high-rank officials and entitled princes were called "fu," the houses of other officials were called "zhai," and the ones of common people were called " jia." The social ranks of owners could be easily recognized by these designations in oral and written language.

For individual buildings, dwelling regulations provided restrictions on scales, roof forms and decoration. (fig. 7) The houses of common people were not allowed to be larger than five bays in depth. The main entrance, which offered the first impression of a house to the public, whose form was a significate expression of hierarchy. Only Upper and Middle classes officials (ranked higher than six) could use a black-head gate (wutou men). ${ }^{26}$ (fig. 7b.2) In earlier Song regulations, common people could only build a main entrance no larger than one bay in width under an overhanging gable roof. New regulations established by 1036 claimed that common people were not allowed to build an individual building as the main entrance. Lady Wenji's return to China: Wenji arriving home provided a detailed description of the main entrance in a scholar's dwelling, threebay in width, two-bay in depth. ${ }^{27}$ (fig. 8 ) The main entrance was followed by a screen wall and a hall on the central axis and was flanked by a small courtyard on each side.

For the roof form, common people could only use an overhanging gable roof, while officials had more choices, such as a gable-and-hip roof and a hip roof, which were more splendid. (fig. 9) The social status of the owner could be recognized by the roof from a distance. For decorations, common people could not use a complicated bracket style

\footnotetext{
${ }^{26}$ The black-head gate is a type of gate that compromised by two columns supporting one beam. The two columns have decorations on top painted black.

${ }^{27}$ Although this painting depicted a history event occurred in the Eastern Han (25 - 220), it was drawn by an imperial painter in the Southern Song on the basis of the image of the Song elite house.
} 
called chonggong, caisson ceiling (zaojing), and corner bracket sets (with one layer of arms) supporting upturned eaves (sipu feiyan). The structure components, such as walls or beams in dwellings of officials and common people could not be painted with colorful paintings on structures, and columns and window frames could not be painted in red.

Dwellings evolve over time according to the changing social and economic climate, architectural techniques, fashion, and material culture. Regulations also changed following the development of dwelling and usually lagged behind that. When new techniques and fashions of dwellings appear, housing regulations will update themselves to the present. Compared with other dynasties, the Song housing regulations were relatively loose. The chart below gathers the regulations of the Tang (618-907), Song (960-1279), and Ming (1368-1644) together. (chart. 1) The housing regulations in the Tang dynasty are the earliest surviving regulations in Chinese history, which are the prototype of regulations in following dynasties including the Song. ${ }^{28}$

According to the chart, the Song regulations were relatively looser than the Tang and Ming regulations. Housing regulations in the Tang and Ming dynasties had a more detailed catalog of ranks than the Song. The Tang regulations were classified by five levels: high rank entitled princes or duke, officials ranked first to third, officials ranked fourth to fifth, officials ranked lower than fifth and common people. The Ming regulations were in five levels: royal members, officials ranked first and second, officials ranked from third to fifth, officials ranked from sixth to ninth and common people. Regulations in both Tang and Ming period provided strict restraints on the number of bays in width and depth of halls and the main entrance almost in every level. The Ming

\footnotetext{
${ }^{28}$ Shiqing Zhang, "Tang 'Yingshan Ling' Dizhai Jinxian Tiaowen Jiexi Yu Jiedu” in Zhongguo Jianzhu Shilun Huikan (Tsinghua University Press, 2010), 144.
} 
even subdivided its scale regulations into the Front Hall, the Main Hall, and the Back Hall separately. However, the Song regulations only had three levels: entitled princes, officials ranked higher than sixth and common people. Also, the Song court offered a considerable freedom of building scale, and only imposed a scale restriction on commoners' buildings. On the other hand, the Song had a stricter regulation on the main entrance of common people than other dynasties. In the Tang, common people were allowed to build an individual building as an entrance, which was forbidden by the Song court after 1036. This regulation seems opposite to the main trend of looser regulations in the Song, probably because of the collapse of ward wall system. In the Tang, most house entrances were placed in the ward, facing inward, so that could only be seen by residents in a closed ward. As the ward walls were removed, house entrances were open to the streets and officials' and common people's house blended with each other in the city. To distinguish commoners' houses from those of elites, commoners were only allowed to use a simple gate as an entrance.

In the Tang dynasty, officials and common people were not allowed to build multistory buildings, either for their home or their workplace in order to protect other houses from being watched. ${ }^{29}$ In the Song dynasty, the multi-story building was not a privilege for entitled princes, but for officials and commoners. These multi-story buildings were also widely used in commercial buildings such as hotels and restaurants. (fig. 10). For the layout, only officials who were granted an audience with the emperor on workdays were allowed to arrange buildings in an axial layout in the Tang. ${ }^{30}$ In the Song, the restriction

\footnotetext{
${ }^{29} \mathrm{Pu}$ Wang, The Tang Huiyao [Institutional History of Tang] (961), Vol. 31.

${ }^{30} \mathrm{Ibid}$.
} 
on the axial layout was abandoned. In some Song paintings, even some simple country houses were depicted in an axial layout.

As handicraft developed during the Song, decorations became much more complicated and varied. Chonggong, zaojing were only allowed in entitled princes and dukes' houses in the Tang, while the use of chonggong, zaojing was extended to officials houses in the Song. Regulations on decorations in the Tang also included some decoration on the roof and beam, which were absent in the Song regulations. In the Ming, more detailed regulations on materials and color were added.

As the Song emperors strengthened civil principle over the military principle, scholarofficials acquired a high social status. Economic prosperity allowed the Song dynasty to survive among its neighbors with strong military power. The Song emperor loosened the housing regulations in order to win over scholar-officials and merchants. Under these loose housing regulations, people had greater freedom in building scales and dwelling layout. 
Chapter 2 Elite houses in new open cities

Urbanization and the failure of the ward system

According to Skinner, the number of county-level units remained remarkably stable throughout imperial China. ${ }^{31}$ However, taking the small territorial area during the Song dynasty into account (nearly half of the Tang's territory), the Song was much more urbanized than other dynasties. Some temporary market places gradually evolved into newly formed towns. Cities became multi-functional urban centers, not only political or military centers but also economic centers.

The population grew rapidly during the Song period, and more and more people lived in cities. In the Tang dynasty, less than twenty cities had more than 100,000 households, while in the Song dynasty, the number increased to at least forty cities. ${ }^{32}$ Kaifeng, as the capital of the Northern Song, had a population that rose to 13 million in the Emperor Reizong's reign ${ }^{33}$ Kaifeng then was the most populous city the world had ever seen until the nineteenth century. ${ }^{34}$

Scholar-officials were likely to move to cities in the Song. Rooted in an agricultural society, Chinese people, including elites, instinctively retained a strong attachment to the rural area. Before the late Tang dynasty, aristocratic clans, which had strong political power, were usually based in a rural area for centuries. Educated elites always praised rural landscapes, yearned for rural life, and criticized noisy cities implicitly or explicitly

\footnotetext{
${ }^{31}$ George William Skinner and Hugh D. R. Baker, The City in Late Imperial China (Stanford University Press, 1977), 19.

${ }^{32}$ Tianhua Huang, Zhongguo Shuishou Zhidu [Chinese Tax System] (Chinese financial\&Economic Publishing House, 2009), 356.

${ }^{33}$ Baozhu Zhou, Songdai Dongjing Yanjiu [Research on the Capital of the North Song] (Kaifeng: Henan University, 1992), 233.

${ }^{34}$ Dieter Kuhn, The Age of Confucian Rule: The Song Transformation of China (Belknap Press of Harvard University Press, 2011), 195.
} 
in the literature. Recluse scholars, such as Tao Yuanming (ca. 352-427), wrote many poems depicting country life and landscape, which suggested their preference to retreat from civil service in cities. In the Song dynasty, elites began to praise cities. ${ }^{35}$ Hong Mai, a famous official in the Southern Song, recorded, "When scholar-officials starting from village gained fame, they would remove their inherited houses and rebuild new houses. Due to the inconvenience of acquiring drugs and food, many scholar-officials moved from villages to counties, then to cities." 36 With the development of commerce, various products and services gathered in cities. Their superiority in supplies, education, and recreation gradually stood out.

The inner structure of cities also experienced a major shift during the Song period. The traditional walled-ward system broke down because of overflowing economic activities. A dramatic shift occurred in the distribution of urban elite houses, and their relationship with other buildings changed. In the earlier ward system, all buildings were distributed in wards and enclosed by ward walls. Economic activities were confined in wards called shi, while other buildings such as houses and administrative offices were in wards called fang. For instance, Chang'an, a capital city in the Tang dynasty, was divided into 108 fang and two shi. (fig. 11) Wards were enclosed by walls which were two meters high, and ward gates on each side of the ward connected inner buildings with outer avenues. ${ }^{37}$ (fig. 12) Every ward served as an administrative unit guarded by soldiers. The ward gate was closed during evening curfew (from dusk to dawn), and people were

\footnotetext{
${ }^{35}$ Liu, Fang. Song Dynasty Double Capital of Urban Culture and Literature Production. PhD diss., Shanghai Normal University, 2008, p. 180

${ }^{36}$ Mai Hong, "Si Ying Shi" in Rongzhai Xubi, Vol. 16.

${ }^{37}$ Chang'an had 110 fang after Emperor Gaozong, then had 109 fang after Emperor Xuanzong.
} 
forbidden to appear on avenues outside the wards during this period. Stores in shi were also closed during evening curfew. Only officials ranked higher than third were allowed to build their main entrance on the ward wall. ${ }^{38}$ Other residents, including commoners and lower officials, had to enter the street from their houses through ward gates.

From the late-Tang to the early-Song, China witnessed a period of wars and unrest, which resulted in a discontinuous and relatively loose municipal administration of urban layout. A large number of illegal structures appeared on the street. When the Song was founded, the Song court wanted to recover the walled-ward system of the Tang dynasty but failed. Fixed sites and time for commercial activities were not suitable for the Song economic booms. The Song court was gradually forced to extend the time and cancel the space limitations for trading. In 965, the court extended the legal market hours to midnight. According to The Eastern Capital: A Dream of Splendor (Dongjing Menghua $L u$ ), fairs in Kaifeng of the Northern Song were finished at 1:00 a.m., and were reopened around 3:00 to 5:00 a.m. ${ }^{39}$

In the reign of Emperor Renzong, stores were allowed to open along the street. In Along the River During the Qingming Festival, stores and vendors frequently appeared on the streets. Compared with the street width of the Tang Chang'an, the streets in the Song Kaifeng, along with various stores, were strongly narrowed. (fig. 13) Although the destruction of ward walls must have been a major operation, no literary sources show the exact time or specific laws of the destruction. Cases about illegal structures which were built on the streets outside the ward walls or legal boundaries were recorded many times

\footnotetext{
${ }^{38}$ Xinze Li, "Song Dynasty Double Capital of Urban Culture and Literature Production” (PhD diss., Shanghai Normal University, 2008), 36.

${ }^{39}$ Yuanlao Meng, Dongjing Meng Hua Lu [The Eastern Capital: A Dream of Splendor] (ca. 1090 - 1150), vol. 7.
} 
throughout the Song dynasty. ${ }^{40}$ Commercial activities spread on streets, and they became narrower and narrower. Due to the extended time and space that was assigned to trading, ward walls' purpose of restraining people's activities for administration became invalid. In the reign of Emperor Huizong, people could pay money to the government to acquire a warrant for building a structure on the street, an action that would have been punished by floggings following earlier laws. Structures on streets became legal if owners could afford them. Eventually, shops invaded every corner of the city, and trading went on day and night. Citizens' daily lives were considerably extended in time and space.

Distribution of elite houses in an open city

As the city structure became more complicated than before, the housing distribution also changed. Chang'an in Tang dynasty was a typical administrative city. It was twice as big as the Northern Song Kaifeng in area, which was too large for its residents to live in. Chang'an's huge scale was not built to satisfy residents' demands, but more for ritual needs and a splendid capital image. Some wards in the south of the city had a few residents and were filled with large areas of fields. ${ }^{41}$ Apparently, living in cities was not as popular during the Tang dynasty as during the Song dynasty. In the Tang dynasty, elite families were rooted in rural areas, and only moved to cities temporarily during their government employment. Once these scholar-officials were retired, they moved back to the suburbs. In the meantime, commercial activities were limited to two wards and were

\footnotetext{
${ }^{40}$ Hequn Li, "Beisong Dongjing Buju Yanjiu" [Research on the Capital Layout of the Northern Song] (PhD diss., Zhengzhou University, 2005), 46-50.

${ }^{41}$ Jijun Xu, Nansong Lin'an Shehui Shenghuo [Social life in Lin'an in the Southern Song] (Hangzhou Press, 2011), 233.
} 
closed during curfew, so that merchants, artisans and other workers were able to live in the suburbs around cities and only came to the cities to make money in the daytime.

The elite dwellings were scattered evenly in the city at the early-Tang, while they were concentrated beside the Imperial Street (Zhuque Street) in the late-Tang, which was closer to their offices. ${ }^{42}$ (fig. 14) The relocation of these huge dwellings implies the low housing density in Chang'an. The Song cities were not only political centers, but also economic centers. Kaifeng and Lin'an, the capital of the Northern and Southern Song had extremely high density. In the Song, due to active trading activities, the city became a hub of various products. The Examination system also made the city a place to take exams and center of educational resources such books. Living in the urban area had many advantages over living in the suburbs. Official-scholars, as well as merchants and artisans preferred to move to cities. According to The Eastern Capital: A Dream of Splendor, "in every avenue and small streets, stores stood shoulder to shoulder, and no vacant buildings left." ${ }^{43}$ Due to the shortage of land, Lin'an even built some three to five-story buildings for rent for the poor. ${ }^{44}$

The clear division of residential and commercial areas was no longer necessary in the Song city. (fig. 15b) The capital of the Northern Song had a three-tiered layout: the outer city, the inner city and the imperial palace. According to the literary resources, elite dwellings in Kaifeng were located both in the inner and outer city. (fig. 15a) There was no mono-core of elite dwellings which appeared in earlier Chinese cities. In the Tang,

\footnotetext{
${ }^{42}$ Xinze Li, “The Research of 'Li Fang' System” (PhD diss., Tianjin University, 2010), 150.

${ }^{43}$ Yuanlao Meng, Dongjing Meng Hua Lu [The Eastern Capital: A Dream of Splendor] (ca. 1090 - 1150), vol. 7.

${ }^{44}$ Jacques Gernet, Daily Life in China, on the Eve of the Mongol Invasion, 1250-1276 (Stanford University Press, 1962), 31- 33.
} 
elite houses were concentrated around the Imperial Street where their offices were located. In the Song, as the city became a multi-functional center, distance from offices was not the main consideration in site selection for a house. The Imperial Street in Kaifeng was along with government offices and stores. It is interesting that some elite houses were just located next to or opposite to restaurants, shops or even brothels. For instance, the house of Cai Jing, a prime minister in the Northern Song, was located near a big wazi. Although merchants acquired a higher social status in the Song, many Song scholars still regarded "market, tea shop and tavern, as places that were full of villains," and if a person "lived in the market for a long time, he would become venal gradually." 45 However, when stores were located on every corner of the city during the Song, the elite had to compromise on house location. At the same time, there is no evidence that specific residential zones for the elites were formed. ${ }^{46}$ Many scholars agreed that the houses of elites and common people were blended. However, by analyzing the location of recorded house locations, the elites preferred locations which were convenient and would not suffered from flooding. ${ }^{47}$

In the Song dynasty, due to abundant supplies, educational resources and services that were concentrated in cities, the elites and labor were more likely to settle in the cities. Spatial and time restrictions on trade were finally removed. As a result, the elite houses, together with commercial buildings and houses of common people shaped an extremely high-density city. Beautiful landscape and tranquil living environment that could be seen

\footnotetext{
${ }^{45}$ Weimin Bao, "Liangsong Chengshi Wenhua Xinlun" [New Disccusion in City Culture in the Song Dynasty] in Journal of Literature, History and Philosophy, No. 5 (2012), 233.

${ }^{46}$ Ye Deng, "A Study on the Spatial Morphology of Dongjing City in North-Song Dynasty" (Master thesis, Tsinghua University, 2004), 87.

${ }^{47}$ Jijun Xu, Nansong Lin'an Shehui Shenghuo [Social life in Lin'an in the Southern Song] (Hangzhou Press, 2011), 233.
} 
in their past rural houses were no longer available in the city. The next chapter will discuss how elites settled themselves in the city. 
Chapter 3 Urban elite houses in the Song

After few chapters introducing social and urban backgrounds of housing, this chapter will further examine what urban elite houses were in the Song dynasty and explore elites' domestic ideal. This chapter will demonstrate how social values, group identity and personal pursuits evolved during the Song and how these factors influenced the design of urban elite houses. The family ritual and fengshui were two social values that influence house design. As the same time, the design and use of these houses were consonant with the group and personal concepts of the elites.

The family ritual and elite houses

In Comprehensive Mirror in Aid of Governance (Zizhi Tongjian), a famous Northern Song scholar-official and historian, Sima Guang (1019-86), wrote at the beginning of the first volume:

Guang said: I heard that the most significant mission of the emperor is to maintain ritual $(l i)$. The most important approach for maintaining ritual is to build a hierarchical system. The most important approach for building this system is to distinguish titles. What is ritual? Ritual is order. ${ }^{48}$

Ritual distinguishes noble and humble, ranks near and distant relatives, regulates the many matters, and structures all activities. Were it not for the names, it would not be apparent; were it not for the accouterments (i.e., the "devices" for making clear rank and position), it would not be manifest. Only after there are names to command

\footnotetext{
${ }^{48}$ Sima, Guang. Zizhi Tongjian [Comprehensive Mirror in Aid of Governance] (1065-86), vol. 1.
} 
them and accouterments to differentiate them will the proper places for superior and inferior be clear. This is the great constant of ritual. ${ }^{49}$

Ritual is a system of ideal ethical orders in ancient China designed by Confucianists. Although the ritual is not legally enforced like laws, it is an influential component of Chinese values in both public and private sphere. As Confucius said, the ritual was not required from the common people. The ritual was especially advocated and implemented by the elite and those who aspired to the elite.

The family ritual was a part of rituals used in family, which detailed the performance and supplies of ceremonies for coming of age, weddings, funerals and ancestral sacrifices. How to conduct these ceremonies influenced the layout of ancestor temples and dwellings. In the Tang dynasty, family rituals were written by and used in large bureaucratic families to regulate behaviors of family members. As these families destroyed in the turmoil before the Song, official-scholars advocated a reconstruction of the ritual system in order to domesticate people. Scholars who were educated in Confucian doctrines re-interpreted the Confucian classics, and drew up ritual guides for the present family. The Song family rituals simplified traditional rituals and became more practical and suitable for people in every class. Both high officials and common people could find a type of rituals to follow.

The Neo-Confucianists paid attention to the visualization of rituals. The Song scholars analyzed the Confucian classics of rituals and drew illustrations to help others to understand these obscure words. A Northern Song scholar Chen Xiangdao's Book of

\footnotetext{
${ }^{49}$ Sima, Guang. Zizhi Tongjian [Comprehensive Mirror in Aid of Governance] (1065-86), vol. 1. trans. by Peter K Bol, 'This Culture of Ours': Intellectual Transitions in T'ang and Sung China (Stanford University Press, 1994), 241.
} 
Rites ( $\mathrm{Li}$ Shu) is probably one of the earliest book containing house plans in illustrations of ceremonies. Later ritual books, such as Illustration about Rites (Yili Tu) by Yang Fu and Interpretation of Li (Yili Jingzhuan Tongjie) by Zhu Xi in the Southern Song and Illustration about Rites (Yili Tu) by Zhang Huiyan in the Qing dynasty, all had similar house plans when illustrating ritual processes in dwellings.

In these illustrations, the main entrance, a courtyard, the main hall were located successively on the axis of a house. (fig. 16) Two steps, east and west, led people from the courtyard to the hall. The hall plan was divided into two parts: the front part (tang), was used as living room and reception room; the back part, which was usually separated into two or three rooms abreast, was a private space for the master. The middle room called shi, and the rest beside it called fang. Ceremony activities were conducted in the courtyard and the hall. For example, in the image of "visiting a friend" in Yang Fu's book Illustration about Rites, the guest and the master should bow to each other out of the main gate, in the main gate, in the courtyard and in the hall. (fig. 17) The master stand at the right side, and the guest at the left side. A Song painting offers a more vivid depiction of this scene. (fig. 18) In front of the entrance, a master is greeting to two guests who just arrived by horse. In the courtyard, the master is greeting to another three guests, making a bow with hands folded in front. The rites were conducted in the houses, in return, the houses were designed to fit these rites. Although the Song elites were usually lived in a dwelling with a more complicated layout rather than the one-courtyard dwellings in these ritual books, the type-halls in front, chambers in the back and accessorial spaces on each side - is the prototype of Chinese houses. 
At the same time, the Song scholars expanded family rituals in daily life, so that an all-encompassing body of practices that could be used to orchestrate all aspects of life. ${ }^{50}$ Rituals were not merely series of ceremonies but also daily practices among family members in everyday life. In Sima Guang's Book of Ritual (Shu Yi), there was a section that referred to rituals in daily life to stress the hierarchy between the older and younger generation, masters and servants, and the segregation of men and women. It was the first time that rituals were applied in private daily life not only ceremonies. ${ }^{51}$ Master Zhu's Family Rituals (Zhuzi Jiayi), one of the most influential ritual manual in imperial China, cited Sima Guang's family rituals in daily life and stressed their importance. ${ }^{52}$ Zhu's family rituals were not only widely adopted in China but also in neighboring Korea and Japan. ${ }^{53}$ This book demonstrated how should different family members behave in the dwelling:

Sons must tell their parents when they go out and personally report their return. When they receive their own guests, they do not seat them in the main room. (If they have guests, the guests sit on the study. If they do not have a study they can use the side of the hall.) They do not tread the eastern steps to the main room to go up and down. ${ }^{54}$

\footnotetext{
${ }^{50}$ Peter K. Bol, 'This Culture of Ours': Intellectual Transitions in T'ang and Sung China (Stanford University Press, 1994), 241.

${ }^{51}$ Meihua Wang, "On the Evolution of Family Rites in Tang and Song Dynasties," Journal of Liaoning University (Philosophy and Social Sciences) 41, no.4 (Jul. 2013): 127-33.

${ }^{52}$ Peter K Bol, Neo-Confucianism in History (Harvard University Press, 2010), 239.

${ }^{53}$ Dieter Kuhn, The Age of Confucian Rule: The Song Transformation of China (Belknap Press of Harvard University Press, 2011), 233.

${ }^{54}$ Xi Zhu, Chu Hsi's "Family Rituals": A Twelfth-Century Chinese Manual for the Performance of Cappings, Weddings, Funerals, and Ancestral Rites, trans. Patricia Buckley Ebrey (Princeton University Press, 2014), 28.
} 
In housing, there should be a strict demarcation between the inner and outer parts, with a middle door (zhong men) separating them. The two parts should share neither a well, a wash room, not a privy. The men are in charge of all affairs on the outside; the women manage the inside affairs. During the day, without good reason the men do not stay in their private rooms nor the women go beyond the inner door. ${ }^{55}$

After combing their hair, washing, and getting dressed, the male servants should sweep the halls and front courtyard; the doorman and older servants should sweep the middle courtyard, while the maids sweep the living quarters, arrange the tables and chairs, and prepare for the toilet of the master and mistress.... The doorman and old servants serve to pass messages and objects between the inner and outer quarters of the house, but they must not be allowed to enter rooms or kitchens at will. ${ }^{56}$ In these rituals above, a dwelling was separated into the outer public part and the inner private part by the middle gate. Guests were confined in the outer part, which contained the main hall, a study for reception, a washroom and a privy. The inner part is the living space for the master's family, including chambers, washrooms, privies and kitchens. Male and Female servants had different workspaces. Male servants except the seniors were not allowed to step into the inner part. A dwelling consisted of series of courtyards guaranteeing relative independence and privacy in each courtyard group.

The family ritual stipulated daily routines for different family members. By compiling these routines together, a complete dwelling formed. The family ritual provided an ideal

\footnotetext{
${ }^{55}$ Xi Zhu, Chu Hsi's “Family Rituals”: A Twelfth-Century Chinese Manual for the Performance of Cappings, Weddings, Funerals, and Ancestral Rites, trans. Patricia Buckley Ebrey (Princeton University Press, 2014), 29.

${ }^{56}$ Ibid., 33.
} 
life mode from the elites' perspective. To further understand the elite house, it is helpful to look into some actual house.

The maps of provincial government offices (fuxie) are the only surviving maps which included depictions of the Song officials' dwellings. Fuxie in the Song dynasty housed the seat of provincial government and the dwelling of the governor's family. The construction of the Song fuxie was sponsored by the court and therefore obeyed the Yingzao Fashi. Fuxie usually covered the whole area of an inner city facing south. ${ }^{57}$ The governor's working space was located on the main axis of the complex, and the living space for his family was located behind or beside his working space. The rest areas were occupied by other provincial administrative offices. The map of fuxie, usually an illustration in city journals, had a complete plan of a high-rank official's house.

When the Song court retreated to the south of Long River, the former fuxie of Jiankang (now Nanjing), located in the inner city, was converted to an imperial palace. A new fuxie was built out of the inner city. The Jiankang city journal, written in the Jingding reign of the Song (1260-4), had a detailed description of the new fuxie with a map. (fig. 19) The description of the fuxie started from the Main Hall (she ting), the most important building on the central axis, which was a conference hall for all officials. ${ }^{58}$ Two corridors flanking the Main Hall were connected to the front buildings. Behind the Main Hall was Qingxin Hall and Zhongshi Buqi Hall on the central axis, which together with two small buildings on each side, framed a compact courtyard. Behind the Zhongshi Buqi Hall, Jingde Hall and two courtyards on the east were the living spaces for the

\footnotetext{
${ }^{57}$ Lin Yuan, Songdai Chengshi Xingtai He Guanshu Zhidu Yanjiu[City Form and Administrative Architecture in the Song Dynasty] (Beijing: China Architecture and Building Press, 2013), 78. ${ }^{58}$ Ibid.
} 
governor's family. Qingxin Hall, Zhongshi Buqi Hall, Jingde Hall were located on the main axis, connected to each other by corridors in the middle.

The courtyard on the north was centered around Furong Pool, which was surrounded by Yulin Hall, Xu Zhai, Jing Zhai, and Xue Zhai. ${ }^{59}$ This group of structures was used for receptions and dining. Behind Jingde Hall and Yulin Hall were some small buildings, which were used as a kitchen, a bathroom, and a restroom, and beyond that was a river. The courtyard on the south was centered around Lotus Pond, which was surrounded by Xiyu Xuan, Youzhu Xuan, Qiushui Furong Xuan.$^{60}$ To the east was another group of buildings leading by Jinxiu Hall. Zhouqin Lou, a multi-story building, was built on Jinxin Hall. In the courtyard in front of the hall were two stones from Jinhua and Bei Pavilion. Halls called Shuixiang flanked the courtyard. (fig. 20) To the east was a public garden.

Another example is the fuxie in the map of Pingjiang (now Suzhou). (fig. 21)

Pingjiang was totally ruined when the Jin battled with the Song. Its fuxie was built during the Shaoxing period (1131-62), and the map of Pingjiang was engraved on a stone in 1229. This fuxie was built in the inner city of Pingjiang. The dwelling of the governor was located behind his working space. The Main Hall was the most important building as it had a double-eaves roof and a peristyle plan. The Dwelling Hall (zhai tang) was for meeting or togetherness of family members. The Small Hall (xiao tang), between the Main Hall and the Dwelling Hall, was used for reception. The hall behind the Dwelling Hall was the chamber of masters, beside which on each side were two small buildings. ${ }^{61}$ This hall connected with the Dwelling Hall and the Small Hall by a corridor in the

\footnotetext{
${ }^{59}$ Zhai is a type of small house usually used as study or dinning hall in dwellings.

${ }^{60}$ Xuan is a type of small house, which usually has large opening on walls and a high ceiling.

${ }^{61}$ Daiheng Guo, Nansong Jianzhu Shi [Architecture in the Southern Song] (Shanghai: Shanghai Ancient Works Publishing House, 2014), 340.
} 
middle. Courtyards between these halls were surrounded by small buildings on both sides. The garden at the back was separated from the front part by a pool. The garden contained rivers, a pond, bridges, stones, and a series of garden buildings such as pavilions and xuan. A multi-story building was built on the wall of the inner city, which could be accessed by a splendid stairway.

Although the fuxie which included an administration function is not purely residence, it also shows some main ideas for living space in the urban area. In these two examples, main halls are arranged on the central axis, and connected to each other by corridors in the middle. These halls and some small buildings on the side shaped a series of courtyards. Halls for reception, ceremonies, or togetherness were in the front, while private space for the family was in the back. Compared to the rigid plan of the front part, gardens were designed in a free plan. Pools, stones, and landscape architecture such as the pavilion were typical elements in gardens.

The painting Tongyin Wanyue Tu showed an inner view of the elite house. (fig. 22) The painting depicts a small hall facing a courtyard, which was the private living space of a dwelling because there was a young woman standing in a hall. The complicated bracket sets on the small hall indicated the high status of the owner. The small hall was connected with a corridor on each side. Behind the small hall was a multi-story building with a double roof which was decorated with animal figurines. Trees and flowers were planted in the courtyard. Taihu stones were located in courtyards in front of and back of the small hall. This painting had many similar elements with fuxie, such as courtyards with stones and a multi-story building. 
The plans of fuxie, and the painting with parts of dwellings and gardens together offer a relatively comprehensive view of elite houses in the Song. Large hall halls were located successively on the axis, and they connected with each other by a corridor in the middle. Small buildings stood beside large halls formed a series courtyard. Landscape architecture, waters and plants were placed in the garden arbitrarily without an axis, which was similar to the later Suzhou gardens. Despite the well-designed garden, some courtyards were also decorated with plants and stones. A multi-story building stood at the back of the dwelling, in which visitors could have a complete view of the garden.

Fengshui for urban houses

Other than the family ritual, fengshui was a significant traditional technique which used in the dwelling design, which may date back to the Zhou dynasty (1100BC 770BC). Fengshui is a technique to evaluate and improve the environment of structure for the living - buildings, and structure for the dead - tombs. It consists of a series of principles in choosing the location and time in building tombs and houses. It also contained approaches in situating villages and cities. Fengshui, reveals not only a sensitivity to recurring patterns of nature and a high level of environmental awareness, but also the self-conscious ways in which people give shape to space. ${ }^{62}$ Although regarded as pseudo-science now in some views, fengshui was largely accepted by royal families, scholars, and common people.

In the Song, Neo-Confucianists deeply involved in the study of fengshui. Many of them even have their theories and treatises in fengshui, such as Zhu Xi. The Song had the

\footnotetext{
${ }^{62}$ Ronald G. Knapp and Kai-Yin Lo, House, Home, Family: Living and Being Chinese (University of Hawaii Press, 2005), 5.
} 
largest group of fengshui practitioner, in the masters of fengshui section in Imperial Encyclopaedia (Gujin Tushu Jicheng), about one third of them in Chinese history lived in the Song dynasty. ${ }^{63}$ Two schools of fengshui theories were founded in the Song, and fengshui reached its paramount in Chinese history during the Song. ${ }^{64}$

"bu ju", using fengshui in the selection and design of homes, was very popular among the elites. This word frequently appeared in poems, articles, and novels. Qiye Dongyu recorded a story about a monk $b u j u$ for Yang Cunzhong. His dwelling was located beside West Lake in Lin'an. The monk symboled the layout of Yang's dwelling as a tortoise. He advised that it would be more auspicious if there was water in the dwelling, while it would be ominous if there was no water in the dwelling, because the tortoise lived in water. Yang accepted his advice and opened up a waterway surrounding the dwelling from the West Lake when he asked for the permission from the emperor. Also, he added a multi-story building to symbolize the head of the tortoise. Eventually, the image of this dwelling was a tortoise, which surrounded by waters, lifting his head looking down West Lake. Surprisingly, the dwelling did not catch fire in more than a hundred years. Later, when the multi-story building was sold to a Daoism temple, the dwelling layout became a tortoise with no head. Just in the year after, the dwelling was burned into ruins. In this story, the emperor, an official, a monk were all involved in this fengshui activities, showing that fengshui enjoyed a great popularity in every class.

Two schools in fengshui, the Form School and the Compass School, were built in the Song dynasty. The Forms School was visually and intuitively based on topographical

\footnotetext{
${ }^{63}$ Xiaoxin He and Jun Luo. Zhongguo Fengshui Shi [History of Fengshui in China] (Jiuzhou Chubanshe, 2008), 250.

${ }^{64}$ Xiaoxin He and Jun Luo. Zhongguo Fengshui Shi [History of Fengshui in China] (Jiuzhou Chubanshe, 2008), 126.
} 
landscape surrounding the dwellings or tombs. ${ }^{65}$ It analyzed a location by observing the shape of mountains, waters, and caves. This school usually has an aesthetic logic, and was popular among the Song scholars. As many scholars were involved in the research of the fengshui, they improved the aesthetics and art value of the Forms School. However, as more people moved to cities, practitioners also recognized that they needed new specific approaches to applying to urban houses, which were not surrounded by mountains and waters as houses in rural areas were. A Song fengshui treatise Boshan Pian provided fengshui approaches for the county houses and urban houses separately. ${ }^{66}$ For the country house, fengshui should focus on the shape and location of water and mountains and the direction of its surroundings. For the urban house, fengshui should focus on the layout and measurements of houses, including the space ahead of the house, the shape and direction of water, the height and wideness of houses and courtyard and the arrangement of buildings. Just as in the story of Yang's dwelling, the monk symbolized the layout of this urban house as a tortoise, and improved the house environment by enhancing the image of the tortoise.

In the Song dynasty, practitioners created the Compass School by introducing Yi in fengshui. The Compass School depended upon complicated calculations by using a compass and various rulers. With the Compass School, fengshui in the Song began to focus on the auspicious meaning of buildings' and furniture's measurements. Shilin Guangji recorded how to use rulers to design auspicious houses. ${ }^{67}$ As mentioned before,

\footnotetext{
${ }^{65}$ Ronald G.Knapp and Kai-Yin Lo, House, Home, Family: Living and Being Chinese, (University of Hawaii Press, 2005), 104.

${ }^{66}$ Huang Miaoying, "Dweling" in Boshan Pian.

${ }^{67}$ Chen, Yuanliang. "Mathematics" in Shilin Guangji (ca. 1264).
} 
the gate, which reflected the social status of its owner, played a crucial role in a dwelling. In fengshui, the gate was regarded as the "throat" of a house, which controlled the circulation of qi. Shilin Guangji recorded three rules, Luban Ruler, Qu Ruler, Xuannv Ruler, working together to calculate the measurement of the door. For example, Luban Ruler is a ruler which was divided into eight segments, and each segment has different auspicious or inauspicious meanings. The best measurements can be achieved by using these three rulers to measure and calculate.

As the urban commerce in the Song dynasties developed, more and more people moved to in cities. Urban dwellings, having high density and little natural surroundings, surely cannot use the same methodology of fengshui as country houses. Fengshui masters, some of those were New-Confucianists, began to adjust traditional approaches like the Forms School and create the Compass Schools in order to achieve a better urban house.

The urban elite houses as images of mind

If buildings and courtyards were deeply influenced by rituals, gardens expressed their owners' pursuits. Gardens are usually regarded as an imitation of the natural landscape. Before the Tang dynasty, private gardens were usually built by aristocrats, and concentrated in capital cities. Gardens in the Tang were usually called "Courtyard with Mountain and Pool" or "Courtyard with Mountain and Pavilion." Small earth mountains and pools were used to imitate a scene in nature. In the meantime, scholars and painters began to become involved in garden design in the mid-Tang. In the Song dynasty, as the social status of scholar-officials rose, scholar gardens sprung up in cities. Their high-level aesthetic considerations contributed to the development of garden designs. Zhou 
Weiquan wrote in The History of Chinese Traditional Gardens, "The mode that landscape poems, landscape paintings and gardens intertwined with each other had already being established in the Song dynasty." ${ }^{98}$ The image from landscape paintings and poems inspired garden design; the scene in gardens was praised by landscape poems, or was endowed with the spirits or thoughts in landscape poems. Northern Song painter Guo Xi argued in "the instruction of landscape painting" section in Pleasure in Forests and Fount (Linquan Gaozhi) that elites loved landscape because they wanted to flee from secular issues. He claimed that a good landscape painting allowed them to enjoy to landscape without going out of buildings. Gardens with waters, stones, and plants are just another method to bring the landscape and pleasure into their home even when the elites moved to cities. ${ }^{69}$ Guo also discussed what was a good landscape in a painting:

It is generally accepted opinion that in landscapes there are those through which you may travel, those in which you may sightsee, those through which you may wander, and those in which you may live. Any painting attaining these effects are to be considered excellent, but those suitable for traveling and sightseeing are not as successful in achievement as those suitable for wandering and living. ${ }^{70}$

Guo argued that an excellent landscape in painting should allow people to travel, to sightsee, to wander and to live. The latter two attributes are more important than the former ones. These rules may also apply to landscape in gardens.

\footnotetext{
${ }^{68}$ Weiquan Zhou, Zhongguo Gudian Yuanlin Shi [History of Chinese Traditional Gardens] (Tsinghua University Press, 1999), 195.

${ }^{69} \mathrm{Guo} \mathrm{Xi}$, "the instruction of landscape painting" in Linquan Gaozhi [Pleasure in Forests and Fount] (ca. 1023-85).

${ }^{70} \mathrm{Guo} \mathrm{Xi}$, "the instruction of landscape painting" in Linquan Gaozhi [Pleasure in Forests and Fount] (ca. 1023-85), trans. by Chris Pallant, "History National Perspectives" in Animated Landscapes: History, Form and Function (Bloomsbury Publishing USA, 2015), 113.
} 
Famous Luoyang Gardens by Li Gefei recorded nineteen famous private gardens in Luoyang, which was the east capital of the Tang dynasty and still was an important city in the Song. Six of these gardens were built abutting houses, two were floral gardens, and the rest were independent gardens for entertainment.

Fuzheng Garden, one garden in Li Gefei's record, was located beside the house of Fu Bi (1004-1083), who was a prime minister of the Northern Song. (fig. 23) He opened this house and garden after he retired from the Song court. Although many huge residential gardens in Luoyang in the Song period were transformed from original ones of the Tang elites, Fuzheng Garden was a new one built in the Song dynasty. Li Gefei introduced Fuzhen Garden garden in the sequence of his wandering in the garden, which is consistent with Guo Shuzhong's idea of "landscape for wandering."

Visitors go into the garden from the house, go east to the Tanchu Pavilion. Then go up to Four View Hall where can have a panoramic view of the garden. To the south, across the Tongjin Bridge, go up to Fangliu Pavilion, visitors can see the Ziyun Hall. Turn right, wandering in the plants more than a hundred steps, then go through the Yinyue Pavilion, visitors can see You Platform, and then arrive Chongbo Xuan. Walk to the north, across Tuyun Cave, visitors are surrounded by bamboos.... ${ }^{71}$

This garden had eight pavilions, three halls, one xuan, two platforms, one bridge, four caves. These structures, together with various plants and waters, created a great sense of nature. Gardens not only imitated the beautiful scene in the countryside, but also created scenes reflecting the scholars' inner world. Scholars from the Song dynasty were likely to give some structures a meaningful name. In Fuzhen Garden, one platform was named

\footnotetext{
${ }^{71} \mathrm{Li}$, Gefei, "Fuzheng Garden” in Record of Famous Luoyang Gardens
} 
after plum blossom, which was a symbol of a pure soul. Another platform was called "tianguang" (skylight), which was a term in Buddhism, means the thinking of time and life. The bridge was called "tongjin" which meant a way to success. One pavilion was called "jianshan" (two mountains are overlapping in perspective), which was a term selected from $Y i$ (a Confucian classic) and a direction term in fengshui. It means being content to with the status quo and not doing exceed one's authority.

Sometimes, elites combined poems with the scene in their garden. Sima Guang created inscriptions or composed poems to describe these structures to associate their building with sages in history. In his Garden of Solitary Enjoyment (Dule Yuan), he made a set of seven poems for the seven scenes in the garden: Reading Hall (Dushu Tang), Fishing Hut (Diaoyu An), Plot for Picking Herbs (Caiyao Pu), Terrace for Seeing Mountains (Jianshan Tai), Pavilion for Playing with Water (Nongshui Xuan), Studio for Planting Bamboo (Zhongzhu Zhai), Pavilion for Watering flowers (Jiaohua ting). Although these names of scenes just merely presented their functions, in each poem he associated one scene with a scholar in history. He used these poems to praise the virtue of seven scholars, but more importantly, to express what kind of person he wanted to be. These titles, inscriptions and poems and articles uplifted these physical forms to symbols which reflected the outstanding personalities of the owners.

Gardens were not only for personal use but also for socializing. Owners invited friends to their homes to compose poems, create paintings, appreciate antiques and watch singing or dancing performance. Houses were a tool to present scholars aesthetic and moral qualities to their friends. The Song painter Li Gonglin's the Picture of Gathering in West Garden is a famous painting depicting a meeting in Wang Shen's west gardens in 
Kaifeng. (fig. 24) Sixteen famous scholars in the Northern Song were gathered in the picture. Although it is hard to know whether this meeting actually happened in history, this painting provides information about what is a scholars' gathering in the Song city.

In the painting, the garden was built with rivers and various plants. From the start, four scholars were sitting or standing around a table, one of which was drawing. A servant was placing antiques on a table preparing for scholars' appreciation. Six scholars were gathered around a stone table composing poems. Two scholars enjoyed music. Two scholars were writing calligraphy in front of a board stood along the river. On the other side of the river, a monk and a scholar, sitting on a rock, probably discussing Buddhism. Apart from sixteen scholars, six servants were also depicted in the painting. This painting provides a visual evidence of what a scholar garden looked like, and what did elites do in the garden.

The elites not only invited friends to their private gardens, but also open their garden to the public sometimes. The Eastern Capital: A Dream of Splendor (Dongjing Menghua $L u$ ) listed a large number of imperial and private gardens which were open to the public on Lantern festival. The Song painting Competition in Jinming Pool (Jinming Zhengbiao Tu) recorded a dragon boat competition in an imperial gardens Jinming Pool. This competition was run in March every year, and open to the public. (fig. 25) In a record of Mengliang Lu:

Jiang Yuanshi built a garden abutting his dwelling. Handsome pavilions and platforms and various flowers and trees are placed in the garden. In the spring month every year, Jiang will open the garden to the public. Trade activities and gamble games are conducted in halls.... Official proclaim wares and antiquity display on the 
east of a hall for appreciation. ... Tea houses and taverns are also introduced in the garden to imitate scenes in villages. This small garden attracts many people. ${ }^{72}$ In this garden, common people could experience the elite culture, and also enjoyed many entertainment activities. Also, the elite was very pleased to display their life and taste to common people.

Houses were not only clusters of buildings for living, but also physical forms of collective consciousness and individual consciousness. Houses were endowed with owners' political ambition or frustration, spirits pursuits and auspicious wishes. Houses help to handle owners' relationship with the society and their inner world.

The Song elites quested not only shelters to live but also private spaces which fit the value of their class and themselves. First of all, the elite house obeyed to the social value. Their houses should have suitable forms, scales and decoration. Their houses served for various daily rituals, so that the segregation between men and women, the relationship between the young and old generation, the master and servants, and the master and the guests could be implemented in their house. Moreover, as the living surroundings changed from the rural area to the city, the elites developed new fengshui approaches applying to the urban houses in order to promote their quality of life.

Furthermore, well-educated elites always had good taste and spirit pursuits. The highdensity city and high political pressure urged them to find a way to relax and relieve themselves physically and physiologically. They introduced the scene they love to their home and express their thoughts and feelings through the buildings and scenes in their

\footnotetext{
${ }^{72} \mathrm{Zimu}$ Wu, “Garden” in Mengliang Lu (ca. 1274).
} 
home. The elites entertained themselves and communicated with their friends through programs in their gardens. These urban houses symbolize the elites' social status by carrying their daily routine of the elite group and the distinctive taste of their own. 
Conclusion

As the Song emperors strengthened civil authority over military authority, scholarofficials acquired a high social status. To win over scholar-officials, the Song emperors offered privilege for them. Official-scholars were given more opportunities and fewer restrictions in many aspects, such as loose housing regulations. The Song elites had greater freedom in building forms, dwelling layouts and decoration.

As the new managers of the empire, scholar-officials designed and maintained new social orders. They bore a responsibility to implement and advertise these orders. Their houses became a showcase for these values.

Scholar-officials gained great political power, as well as political pressure. They needed a place to isolate themselves from the bustling city and political strife. They designed homes as a physical and psychological reserves for themselves. Good salaries paid by the court and extra income from their involvement in trade allowed them to build gardens containing various plants, landscape architecture, waters and stones. They named the buildings with further meanings and composed poems for the scenes in their house in order to visualize their inner worlds.

With a high social rank and a strong voice, the elite loved to advertise their taste in the dwelling. They simplified the ritual so that could be followed by common people. They opened their gardens to the public and invited common people to visit. In the meantime, the open city structure led to frequent communications between elites and common people, which allowed common people to have a glimpse of the elite life. Abundant products allowed common people to buy affordable alternatives to imitate elites in daily life. They could buy the same items or cheap copies of what elites have. In 
their small home, they liked to plant a few bamboo, open a small pool with lotuses or golden fishes. ${ }^{73}$ As the main history recorder, the elites were likely to stress their authority in taste. Citizen culture's influence on the elite was seldom recorded. A literature source recorded a dwelling of common people, "lives in the back of a fang in the southeast of inner city which is a very bustling place. There was a garden and a pavilion. Both bamboo and flowers were planted in the garden, although not much. He can wander, enjoy the beautiful view, invite friends and rest at home." ${ }^{.74}$ Learning from the elite house, common people introduced plants, landscape architecture and waters in their homes. However, common people only imitate forms and did not recognize and create the further meaning behind these scene in the elite house. That was one of the major difference between the elite house and common people's house, in spite of their different material conditions. For the elite, houses bore the image of their mind.

\footnotetext{
${ }^{73} \mathrm{Mu}$ Qian, Guoshi XinLun [New Opinions on China History] (Beijing: Joint Publishing, 2012), 365.

${ }^{74}$ Yucheng Wang, Xiaochu Ji (ca. 1000).
} 


\section{Bibliography}

Ancient Chinese Painting Research Center of Zhejiang University. Song Hua Quan Ji [Complete Song Paintings]. Hangzhou: Zhejiang University Press, 2010.

Bao, Weimin, "Liangsong Chengshi Wenhua Xinlun” [New Discussion in City Culture in the Song Dynasty] in Journal of Literature, History and Philosophy, No. 5, 2012, 95-107.

Bary, William Theodore De. The Liberal Tradition in China. Chinese University Press, 1983.

Bol, Peter K. 'This Culture of Ours': Intellectual Transitions in T'ang and Sung China. Stanford University Press, 1994.

Bol, Peter K. Neo-Confucianism in History. Harvard University Press, 2010.

Chen, Lai. Song Ming Lixue [New-Confucianism in the Song and Ming dynasty]. East China Normal University Press, 2004.

Chen, Yuanliang. Shilin Guangji. Ca. 1264.

Deng, Ye. "A Study on the Spatial Morphology of Dongjing City in North-Song Dynasty." Master thesis, Tsinghua University, 2004.

Ebrey, Patricia Buckley. The Cambridge Illustrated History of China. Cambridge University Press, 2010.

Fong, Wen. Beyond Representation: Chinese Painting and Calligraphy, 8th-14th Century. Metropolitan Museum of Art, 1992.

Gernet, Jacques. Daily Life in China, on the Eve of the Mongol Invasion, 1250-1276. Stanford University Press, 1962.

Guo, Daiheng. Nansong Jianzhu Shi [Architecture in the Southern Song], Shanghai: Shanghai Ancient Works Publishing House, 2014.

Guo, Daiheng. “The Liao, Song, Xi Xia and Jin” in Chinese Architecture, edited by Nancy S. Steinhardt, 135-89. Yale University Press, 2002.

Guo, Dongge. "The Features Research of Luoyang Private Garden Title in the Northern Song Dynasty.” Master Thesis, Henan Agriculture University, 2013.

Guo, Xi, Linquan Gaozhi [Pleasure in Forests and Fount], ca. 1023-85.

He, Xiaoxin, and Jun Luo. Zhongguo Fengshui Shi [History of Fengshui in China], Jiuzhou Chubanshe, 2008.

He, Zhaoquan. Nansong Mingren Yu Lin'an [Celebrities and Lin'an in the Southern Song], Hangzhou Press, 2010. 
Huang, Tianhua, Zhongguo Shuishou Zhidu [Chinese Tax System], Chinese financial\&Economic Publishing House, 2009.

Jr, Robert E. Harrist. "Site Names and Their Meanings in the Garden of Solitary Enjoyment." The Journal of Garden History 13, no. 4 (December 1, 1993): 199212.

Knapp, Ronald G. China's Vernacular Architecture: House Form and Culture. Honolulu: University of Hawaii Press, 1989.

Knapp, Ronald G., and Kai-Yin Lo. House, Home, Family: Living and Being Chinese. University of Hawaii Press, 2005.

Kuhn, Dieter. The Age of Confucian Rule: The Song Transformation of China. Belknap Press of Harvard University Press, 2011.

Li, Gefei, "Fuzheng Garden" in Record of Famous Luoyang Gardens.

Li, Hequn. "Beisong Dongjing Buju Yanjiu" [Research on the Capital Layout of the Northern Song]. PhD diss., Zhengzhou University, 2005, 46-50.

Li, Jie. Yingzao Fashi. 1103.

Li, Xinze. “The Research of 'Li Fang’ System.” PhD diss., Tianjin University, 2010.

Liang, Jianguo, The relationship between official-scholars in Bianjing in the Northern Song, Beijing: China Society Science Publishing House, 2016.

Liu, Fang. "Song Dynasty Double Capital of Urban Culture and Literature Production." $\mathrm{PhD}$ diss., Shanghai Normal University, 2008.

Meng, Yuanlao. Dongjing Meng Hua Lu [The Eastern Capital: A Dream of Splendor], ca. 1090-1150.

Pallant, Chris. "History National Perspectives" in Animated Landscapes: History, Form and Function. Bloomsbury Publishing USA, 2015, 73-142.

Qi, Xia. Zhongguo Jingji Tongshi: Songdai Jingji Juan [History of Chinese Economy: the Song dynasty], Economy Daily Press, 1999.

Qian, Mu, The Outline of Chinese History. Commercial Press, 2011.

Qian, Mu. Guoshi Xinlun[New Opinions on China History], Beijing: Joint Publishing, 2012.

Si, Daerhan, "The Research of Architectural Image and Origin in Tang and Song Dynasty Painting", Master thesis, Xi'an University of Architecture and Technology, 2015.

Sima, Guang. Zizhi Tongjian [Comprehensive Mirror in Aid of Governance]. 1065-86, Vol. 1. 
Skinner, George William, and Hugh D. R. Baker. The City in Late Imperial China. Stanford University Press, 1977.

Tan, Gangyi. Liangsong Shiqi De Zhongguo Minju Yu Juzhu Xingtai [Chinese Vernacular Architecture and Settlements in Song Period]. Nanjing: South East University Press, 2008.

Toqto'a, "Records of Carriages and Apparel", in The History of Song, 1343.

Wang, Pu. Tang Huiyao [Institutional History of the Tang], 961, Vol. 31.

Wang, Caiqiang. Data Rebuilt of Chang'an. Beijing: China Architecture and Building Press, 2006.

Wang, Guixiang. Zhongguo Gudai Jianzhu Jizhi Guimo Yanjiu [Architecture Site Scales in Traditional China]. Beijing: China Architecture and Building Press, 2008.

Wang, Meihua. "On the Evolution of Family Rites in Tang and Song Dynasties," Journal of Liaoning University (Philosophy and Social Sciences) 41, no.4 (Jul. 2013): 127-33.

Wang, Ying, The Amalgamation Between The Aesthetics Culture and Daily Life in Song Dynasty. Master Thesis, Lanzhou University, 2008.

Wang, Yucheng, Xiaoxu Ji, ca. 1000.

Wu, Zimu, Mengliang Lu, ca. 1274.

Xia, Baojun, "Lun Dongdai Shimin Wenhua de Chuanbo Yu Xiaofei Bianqian" [The Spread and Consumption Change of Citizen Culture in the Song] in Qiusuo, No. 6, 2011, 249-51.

$\mathrm{Xu}$, Biao. Liangsong Wuzhi Wenhua Yinlun [Material Culture in the Song dynasty]. Nanjing: Jiangsu Meishu Chubanshe, 2007.

$\mathrm{Xu}$, Jijun. Nansong Lin'an Shehui Shenghuo [Social life in Lin'an in the Southern Song], Hangzhou Press, 2011.

Yang, Xiaoshan. Metamorphosis of the Private Sphere: Gardens and Objects in TangSong Poetry. Harvard University Asia Center, 2003.

Yongwen. Songdai Shimin Shenghuo [Urban Life in the Song Dynasty]. Beijing: China Society Publishing House, 1999.

Yuan, Jing. "Guanyu Tangdai Zhuzhai de Jige Wenti" [Issues on Houses in the Tang dynasty]. PhD diss., Capital Normal University, 2007.

Yuan, Lin. Songdai Chengshi Xingtai He Guanshu Zhidu Yanjiu [City Form and Administrative Architecture in the Song Dynasty] Beijing: China Architecture and Building Press, 2013. 
Zhang, Hongjie. Zhongguo Guomin Xing Yanbian [The Transformation of Chinese Personality], Hunan Art Press, 2016.

Zhang, Shiqing. "Tang 'Yingshan Ling' Dizhai Jinxian Tiaowen Jiexi Yu Jiedu” in Zhongguo Jianzhu Shilun Huikan, Tsinghua University Press, 2010.

Zhang, Yongshuai, "The Research on Residence in Chang'an in the Tang Dynastry," Master Thesis, Shanxi Normal University, 2006.

Zhong guo di fang zhi zhi dao xiao zu. Zhongguo Difang Zhi [Chinese Local Chronicles]. Beijing: Zhong guo di fang zhi zhi dao xiao zu, 2004.

Zhou, Baozhu. Songdai Dongjing Yanjiu [Research on the Capital of the North Song]. Kaifeng: Henan University, 1992.

Zhou, Weiquan. Zhongguo Gudian Yuanlin Shi [History of Chinese Traditional Gardens]. Tsinghua University Press, 1999.

Zhou, Yinhe. Jingding Jiankang Zhi [Local Chronicles of Jiankang in the years of Jingding], ca. 1260-4.

Zhu, Ruixi, Bangwei Zhang, Chongbang Cai, and Zengyu Wang. A Social History of Medieval China. Cambridge University Press, 2016.

Zhu, Xi. Chu Hsi's "Family Rituals": A Twelfth-Century Chinese Manual for the Performance of Cappings, Weddings, Funerals, and Ancestral Rites. Translated by Patricia Buckley Ebrey. Princeton University Press, 2014. 
Glossary

Along the River During the Qingming Festival 清明上河图

Bao Weimin 包伟民

Boshan Pian 博山篇

Chen Xiangdao 陈祥道

Chen Yinke 陈寅恪

chonggong 重栱

Dongjing Menghua Lu 东京梦华录

dule yuan 独乐园

fang 坊

$\mathrm{Fu} \mathrm{Bi}$ 富燩

$\mathrm{Fu}$ 府

Furong Pool 芙蓉池

fuxie 府廨

Guo Daiheng 郭黛姮

Guo Xi 郭熙

Jia 家

Jianshan 兼山

Jing Zhai 静斋

Jingde Hall 静得堂

Jinming Zhengbiao Tu 金明池争标图

Li Gefei 李格非

Li Shu 礼书

Linquan Gaozhi 林泉高致

Luban Ruler 鲁班尺

Mengliang Lu 梦梁录

Qingxin Hall 清心堂

Qiushui Furong Xuan 秋水芙蓉轩

Qu Ruler 曲尺

Regulations of Housing 臣庶室屋制度 she ting 设厅 $s h i$ 市

Shu Yi 书仪

Sima Guang 司马光

sipu feiyan 四铺飞檐

Tan Yigang 谭毅刚

Tianguang 天光

Tongjin 通津

Tongyin Wanyue Tu 桐阴玩月图

Lady Wenji's return to China: Wenji

arriving home 文姬归汉图

xiao tang 小堂

Xiaoxu Ji 小畜集

Xiyu Xuan 喜雨轩

Xu Zhai 恕斋

xuan 轩

Xuannv Ruler 玄女尺

Xue Zhai 学斋

Yang $\mathrm{Fu}$ 杨复

Yili Tu 仪礼图

Yili Jingzhuan Tongjie 仪礼经传通解

Youzhu Xuan 有竹轩

Yulin Hall 玉麟堂

zaojing 藻井

zhai tang 宅堂

Zhai 宅

Zhongshi Buqi Hall 忠实不欺堂

Zhu Xi 朱喜

Zhuque Street 朱雀大街

Zhuzi Jiayi 朱子家礼 
Image

Fig. 1. The maps of the Northern and Southern Song and their capitals.

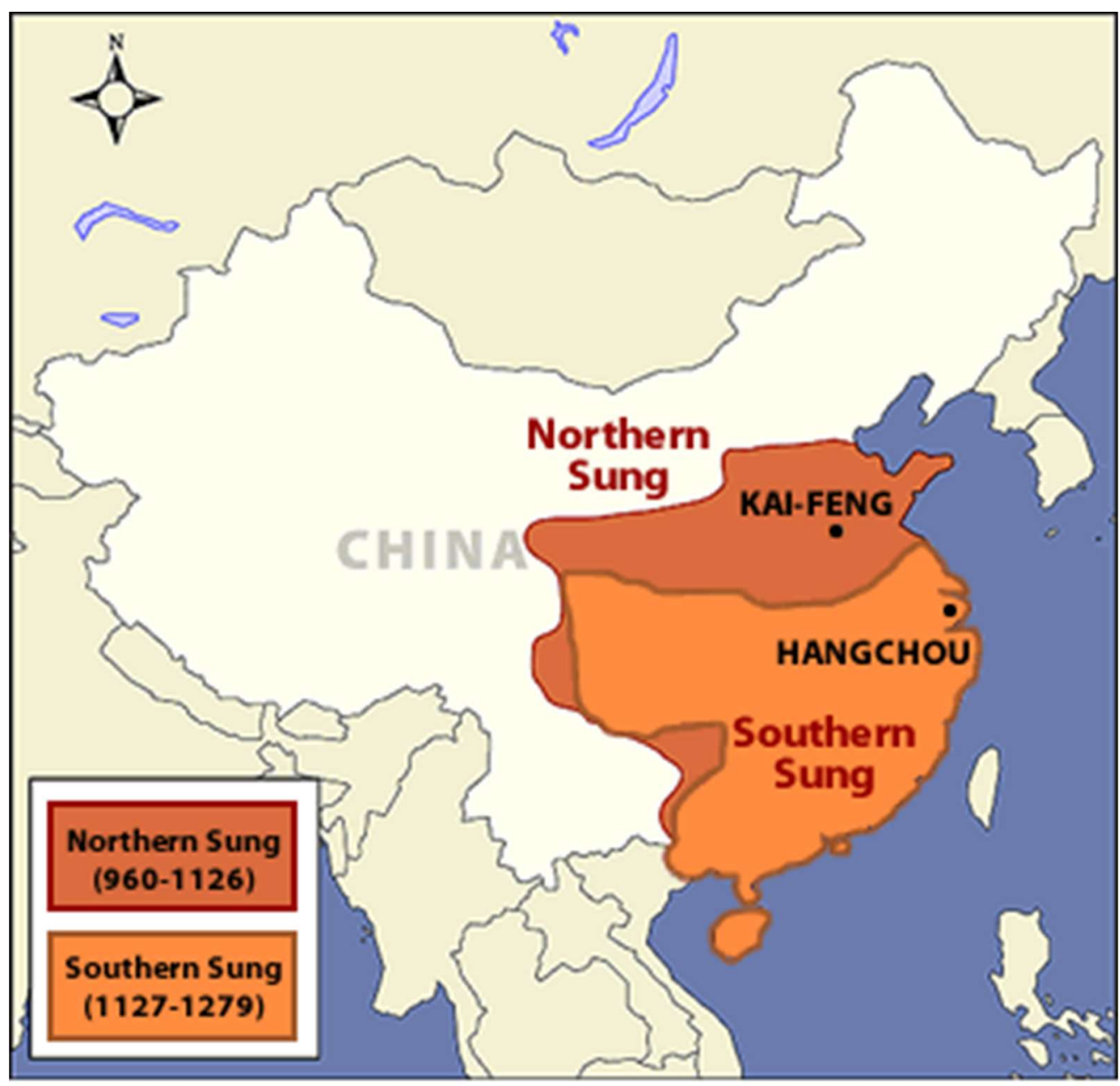


Fig. 2. Hualin Temple, a surviving Song Temple.

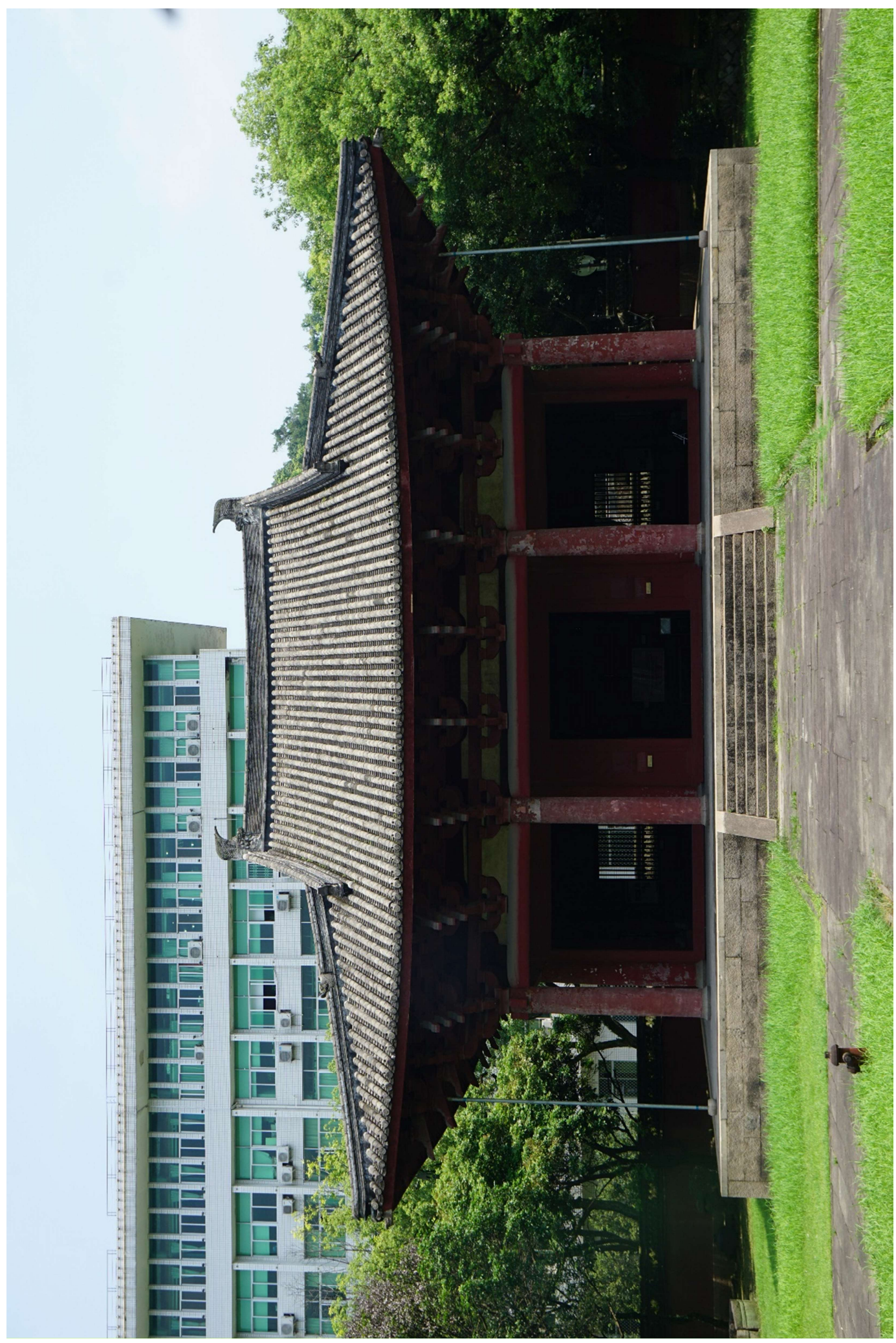


Fig. 3. The Dwelling of Xu (a Song Emperor son-in-law), which was built from the Song.

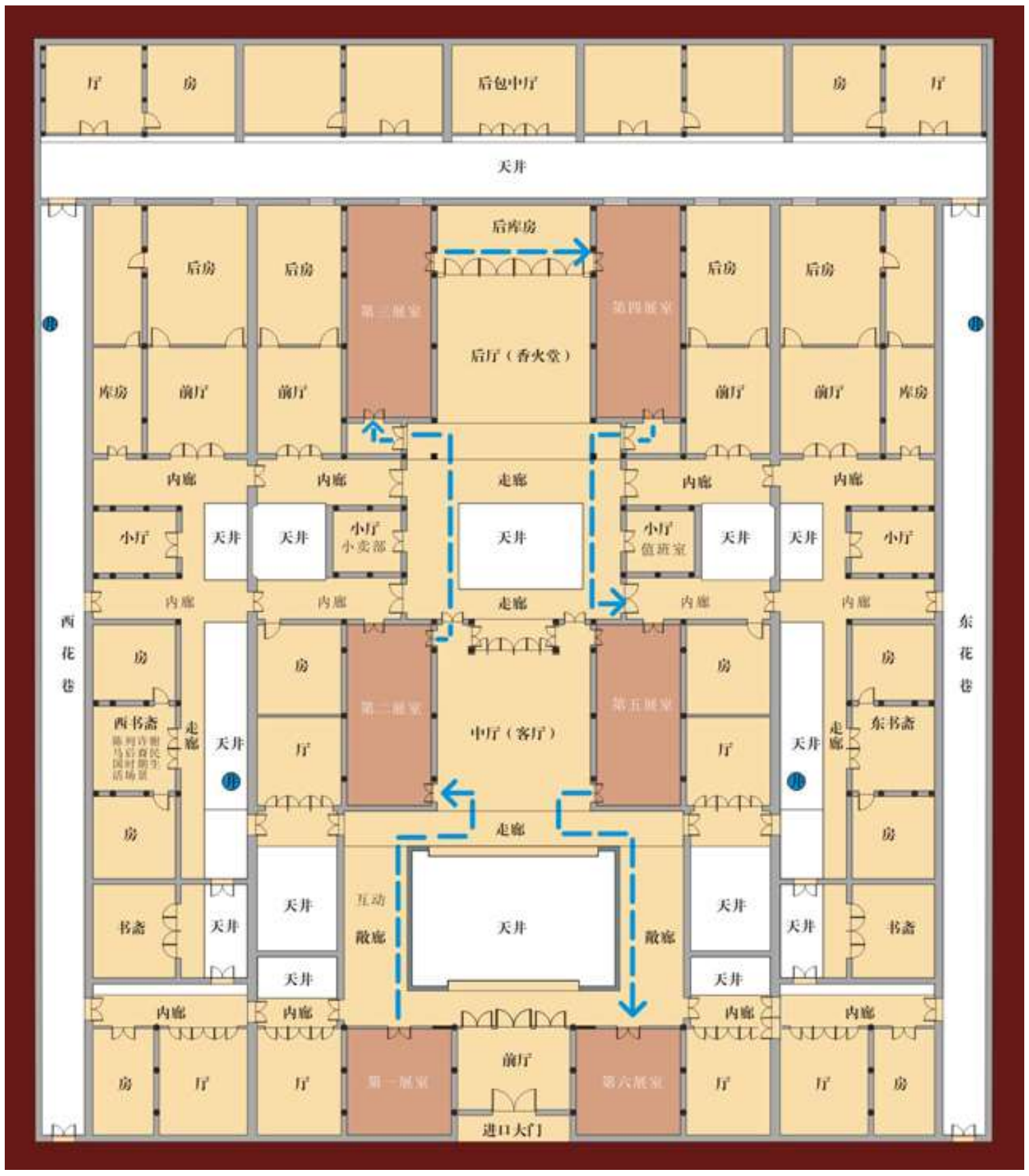


Fig. 4. Along the River During the Qingming Festival.
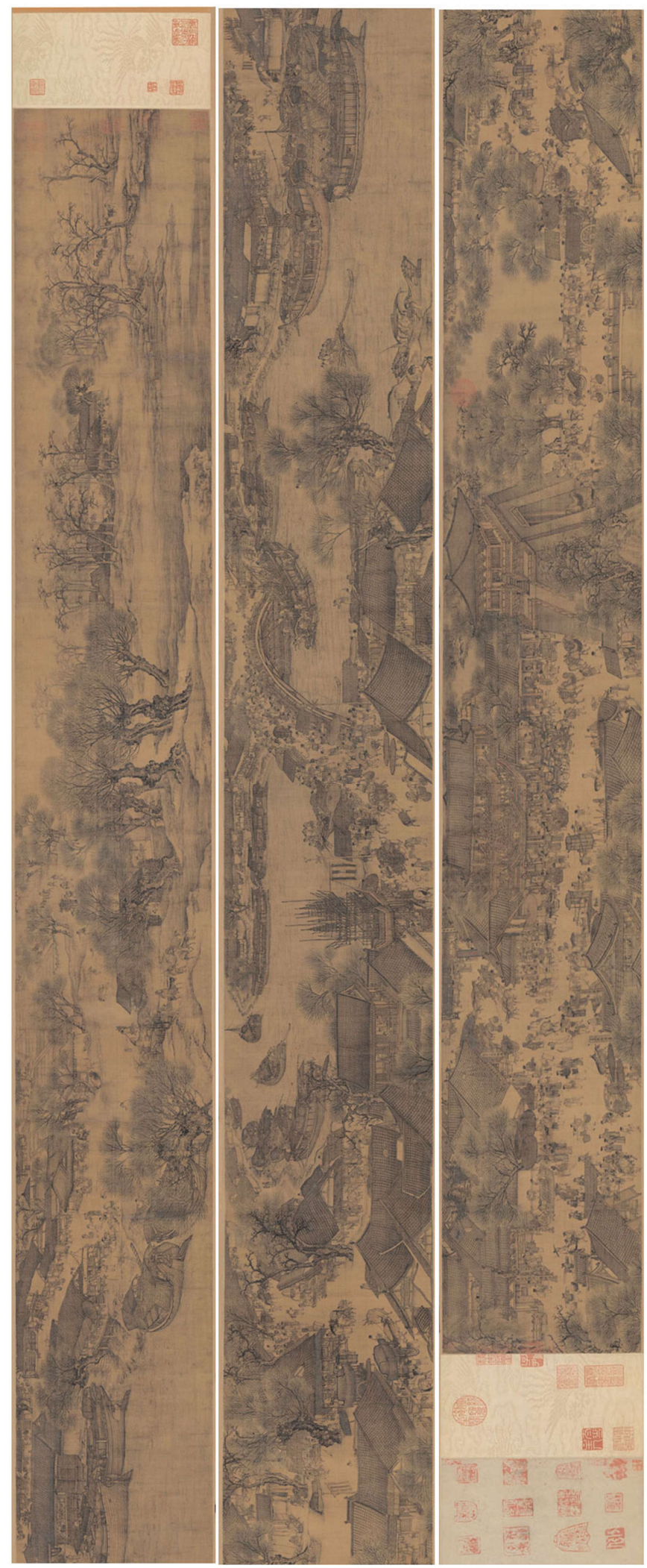
Fig. 5. Module in Yingzao Fashi.

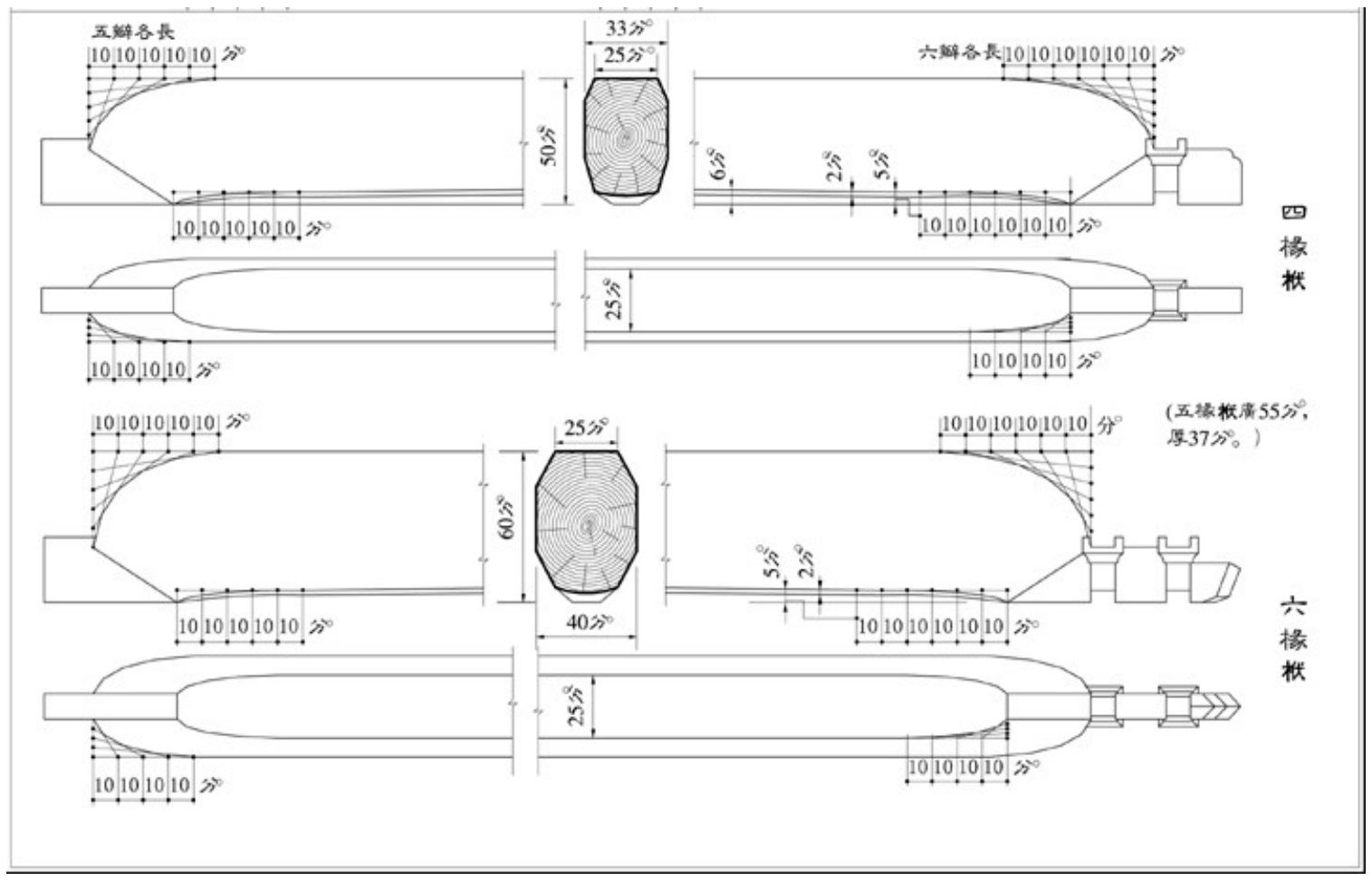


Fig. 6. Removable lattice window.




Fig. 7. Buildings for different classes.

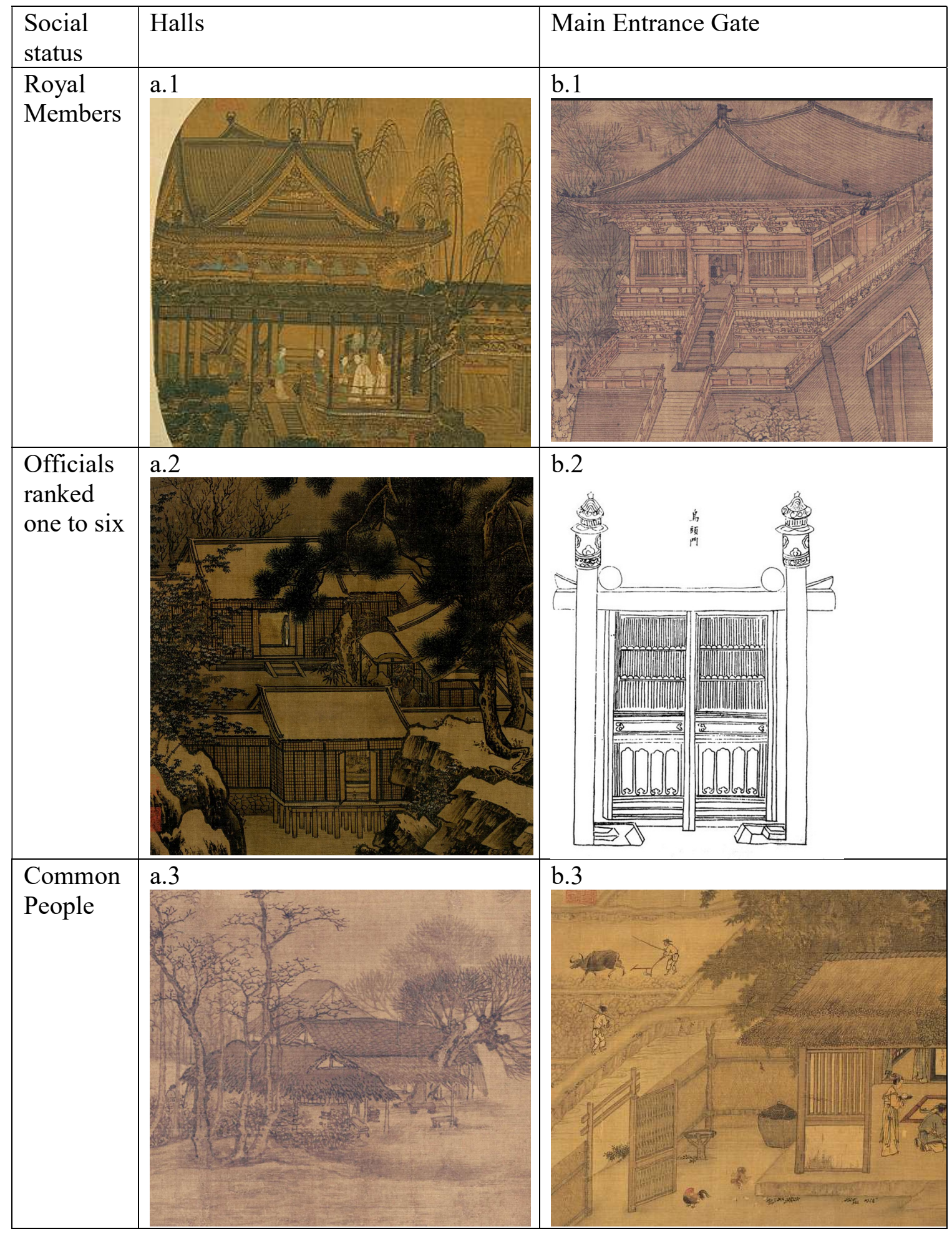


Fig. 8. Detail of Lady Wenji's return to China: Wenji arriving home.

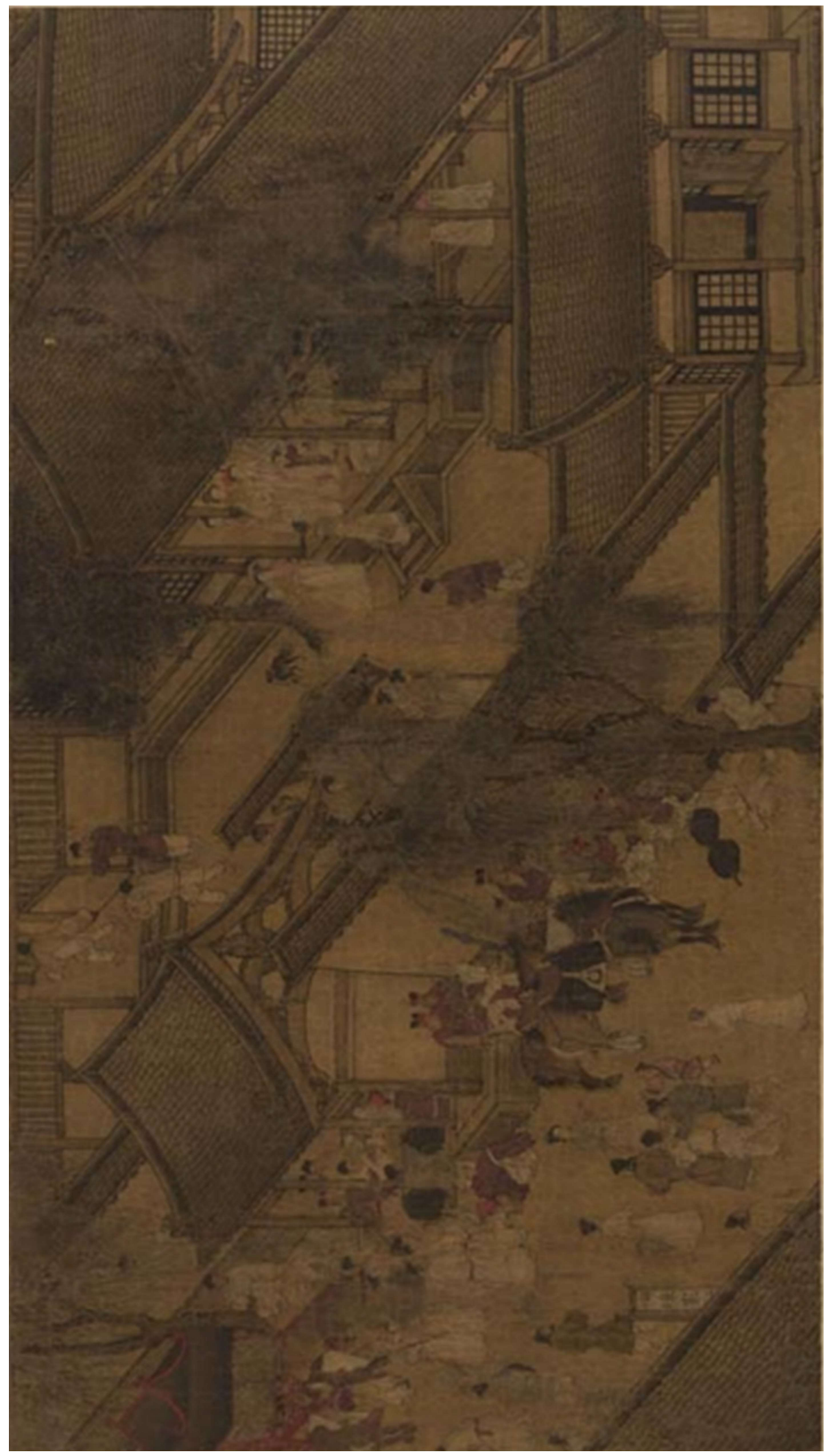


Fig. 9. Type of Roof.
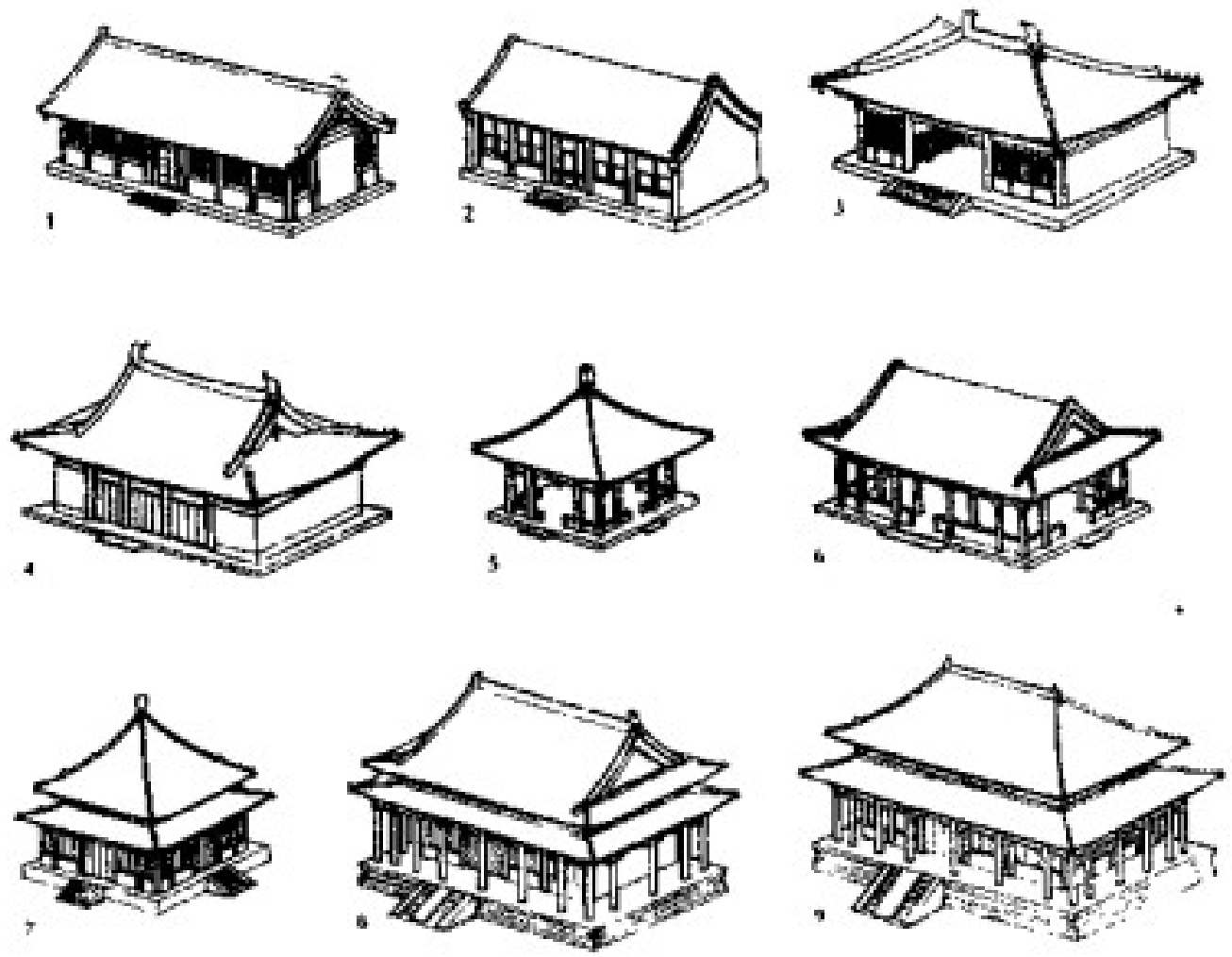

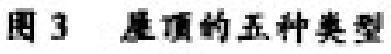

1 数山; 2 玻山; 3 在

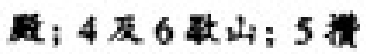

头; 7-9全刹为 5 和

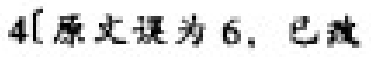

正了度 3 的敦式。
3 Five types of roof

1. overhanging gable roof, 2 . flush gable roof, 3. hip roof, 4and 6. gable - and hip roofs, 5. pyramidal root, 7 9. double-eaved versions of 5, 4, and 3 respectively. 
Fig. 10. A three-story building used as restaurant in Along the River During the Qingming Festival.

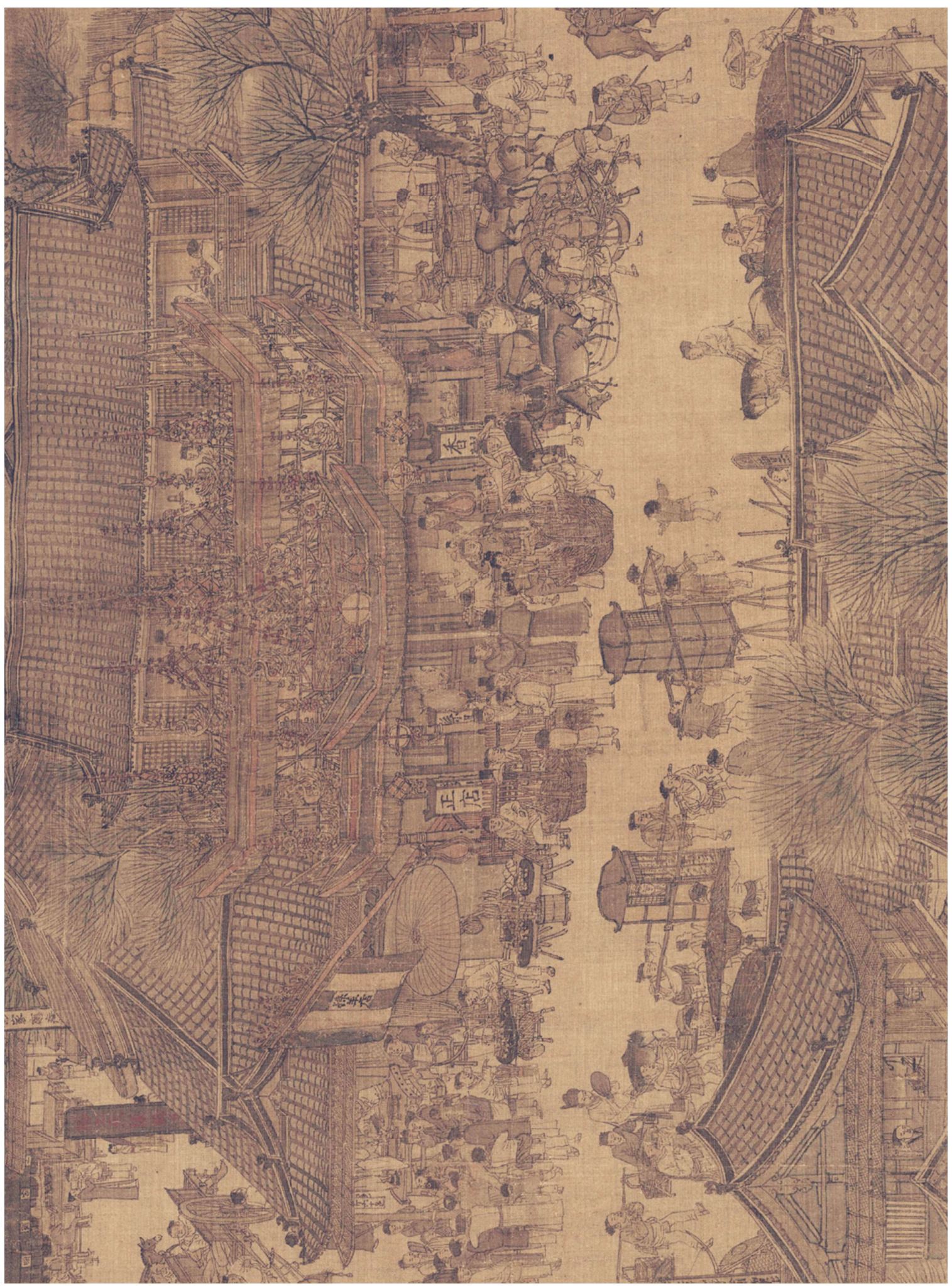


Fig. 11. Plan of Chang'an in the Tang dynasty.

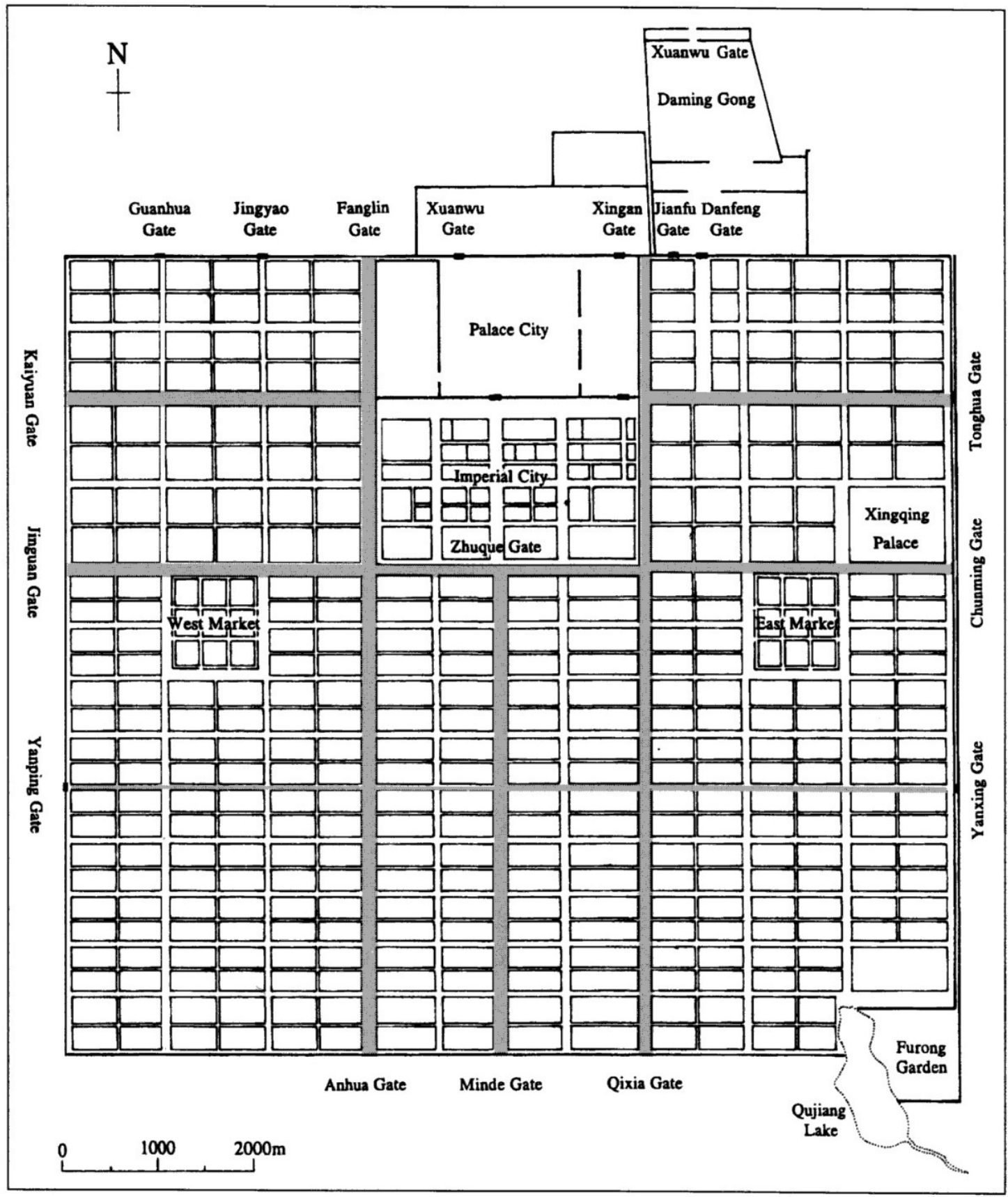


Fig. 12. A ward in Chang'an.

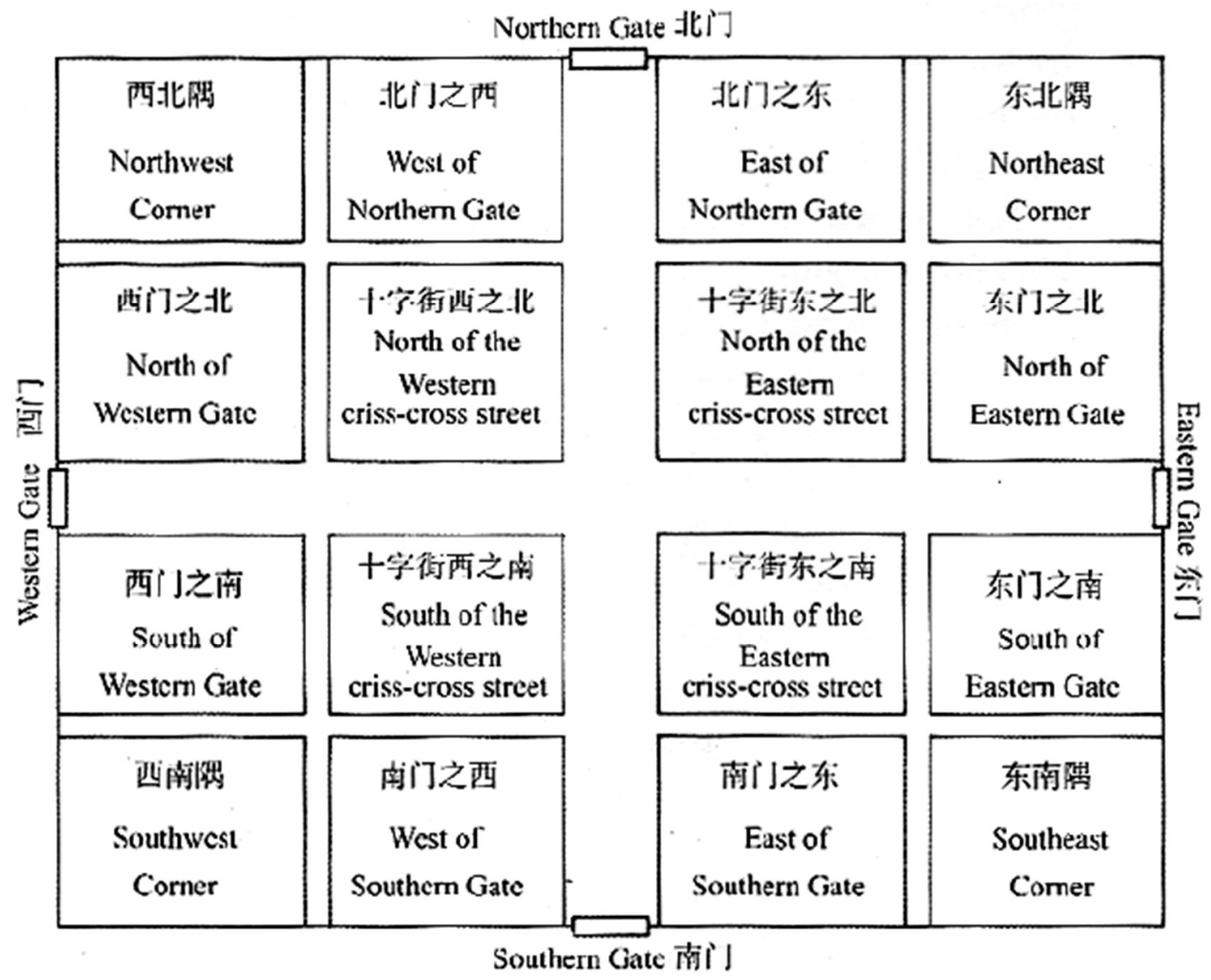


Fig. 13. The section of the street in the Tang Chang'an (above) and the Song Kaifeng (below).

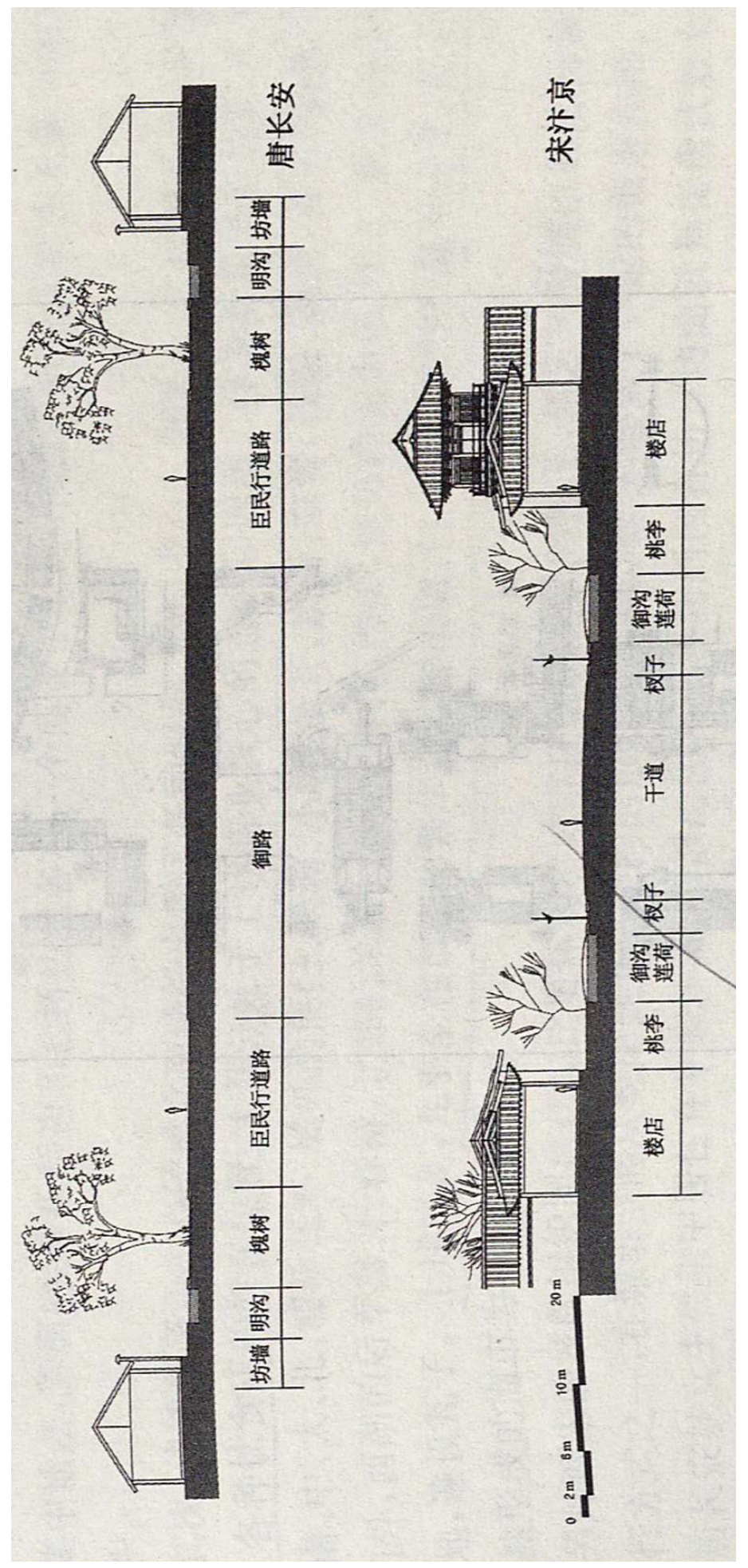


Fig. 14. Distribution of urban elite houses in early, mid, and later Tang Chang'an, dots shows the amount of elite houses in each ward.

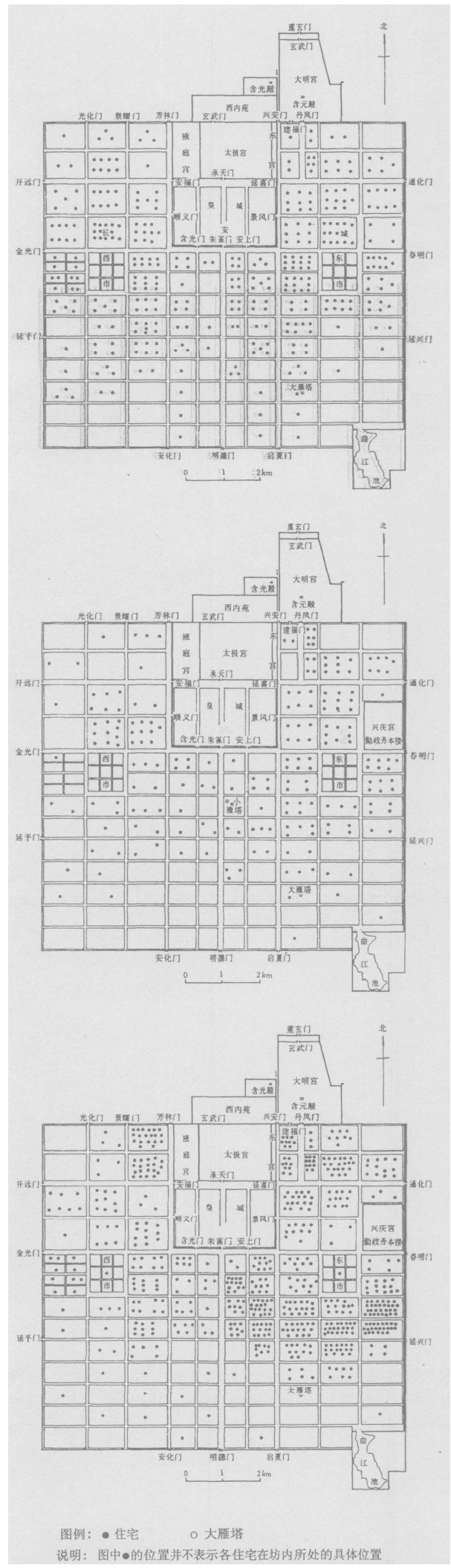


Fig. 15. a. Distribution of elite dwellings in Kaifeng (Hatched in dark grey), b. Land use in Kaifeng, according to literature resource, dwellings in yellow, commercial area are in blue, palace and royal park are in red, religious buildings are in orange.
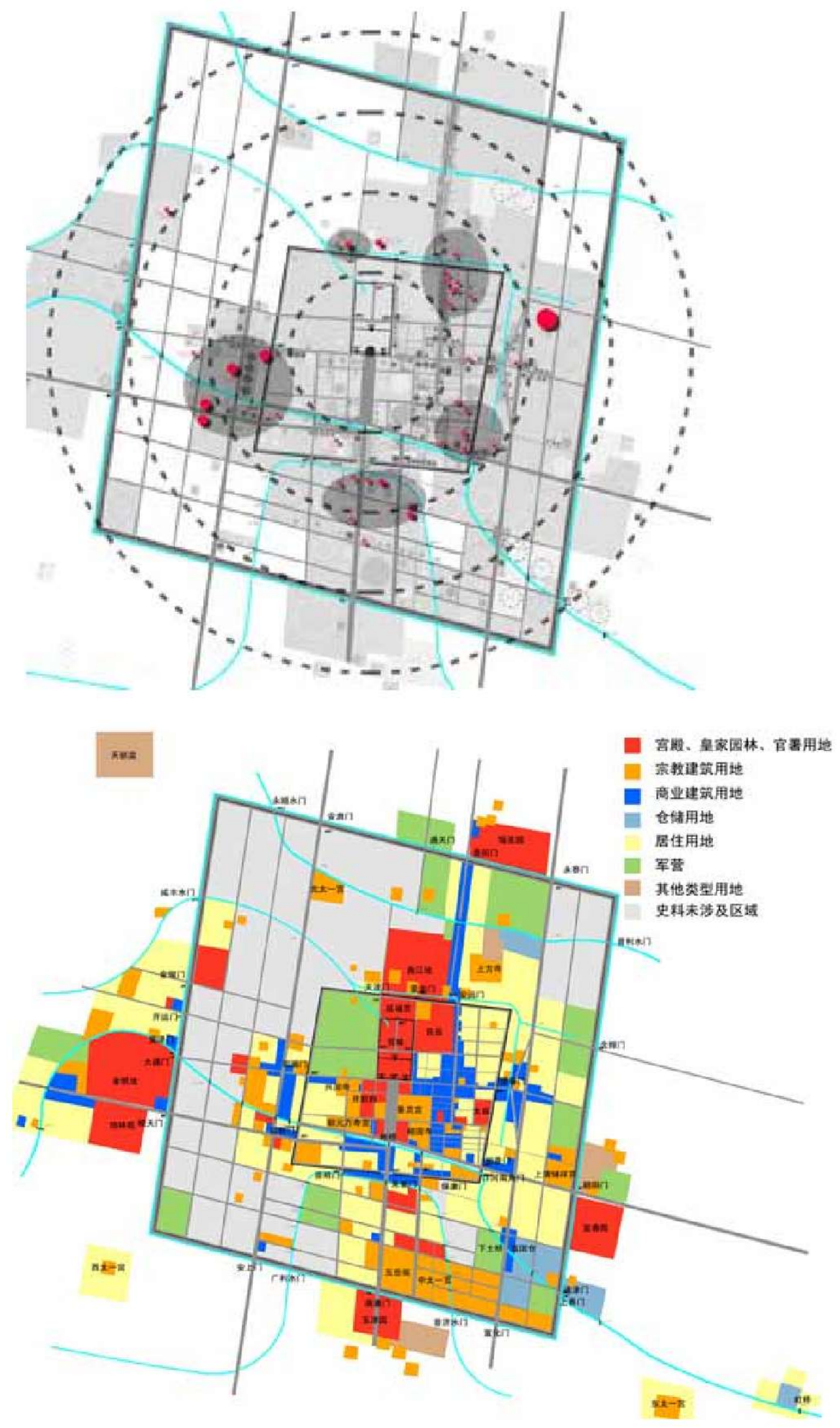
Fig. 16. A house plan in Book of Rites.

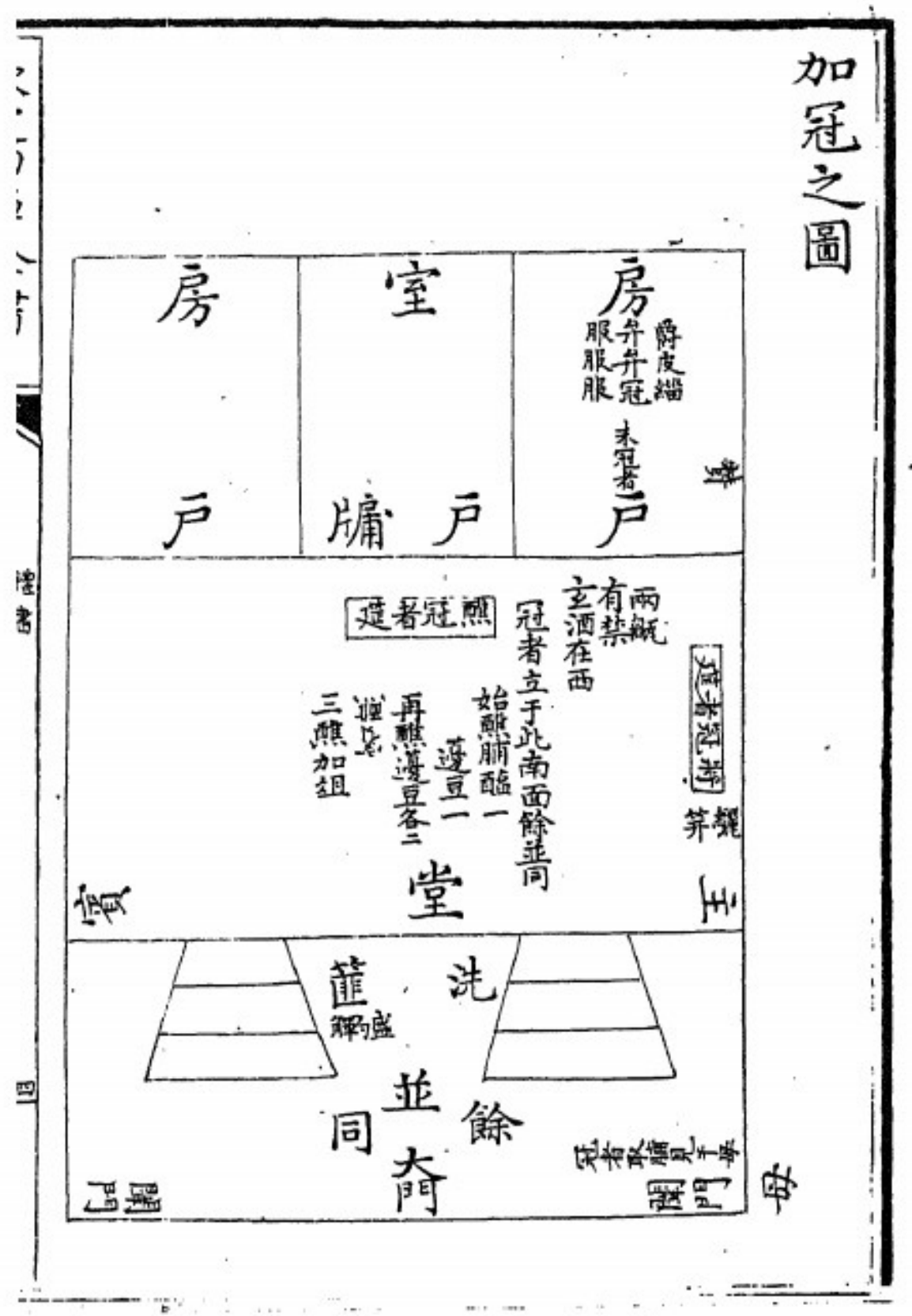


Fig. 17. An illustration about about "Visting a friend" in Illustration about Rites by Yang Fu.

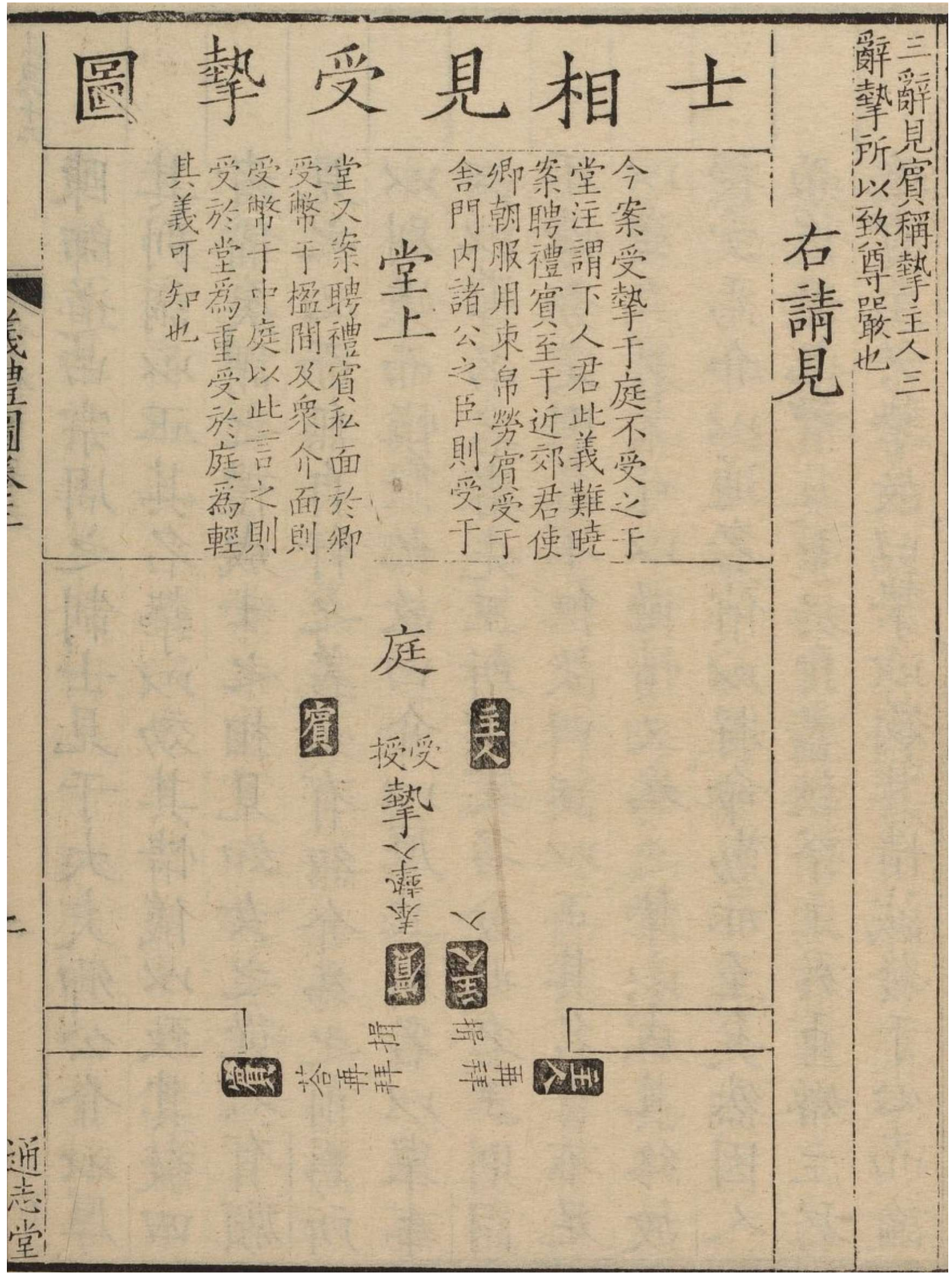


Fig. 18. Suichao Tu by Li Song.

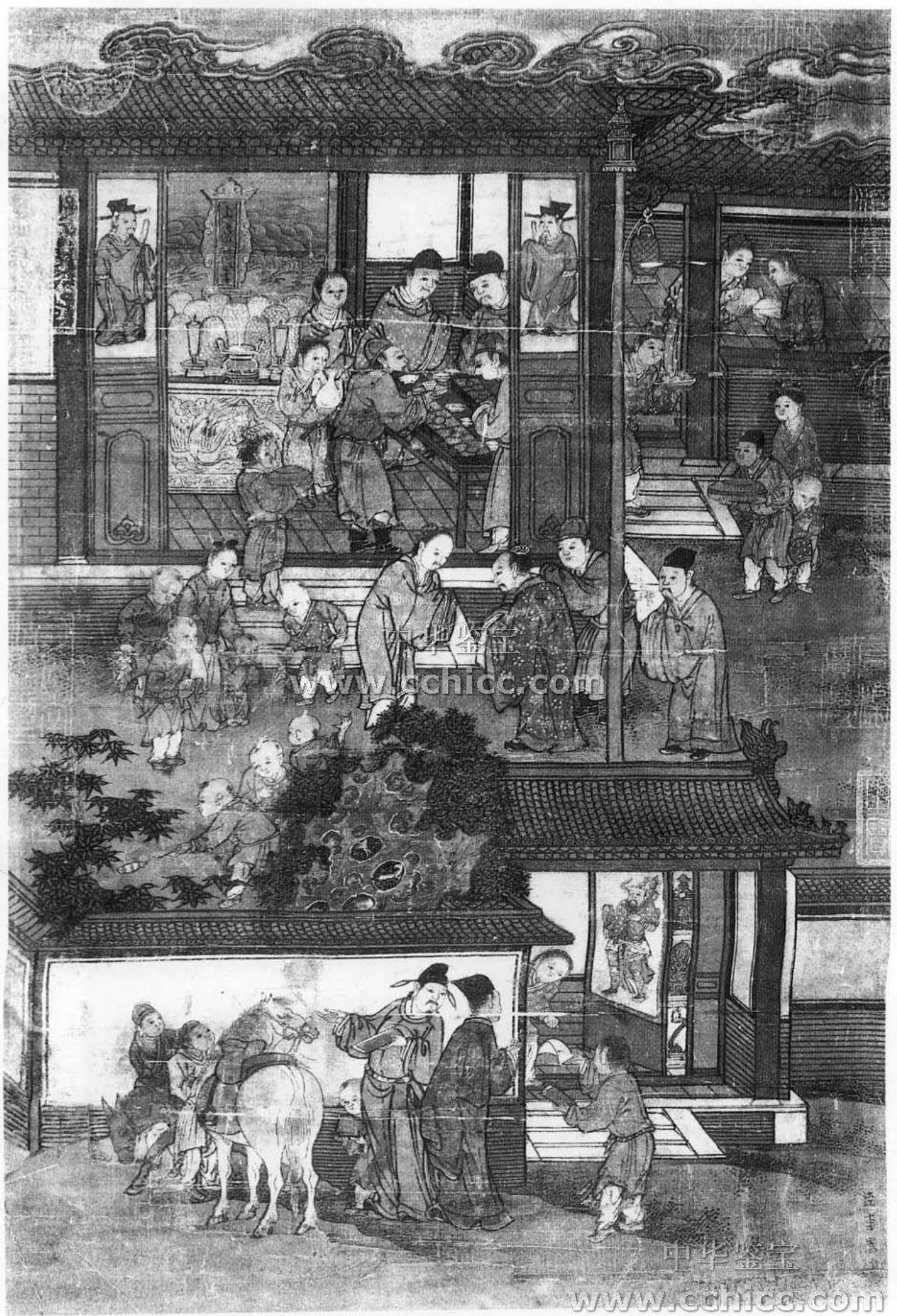


Fig. 19. The map of Fuxie of Jiankang in Local Chronicles of Jiankang in the years of Jingding.

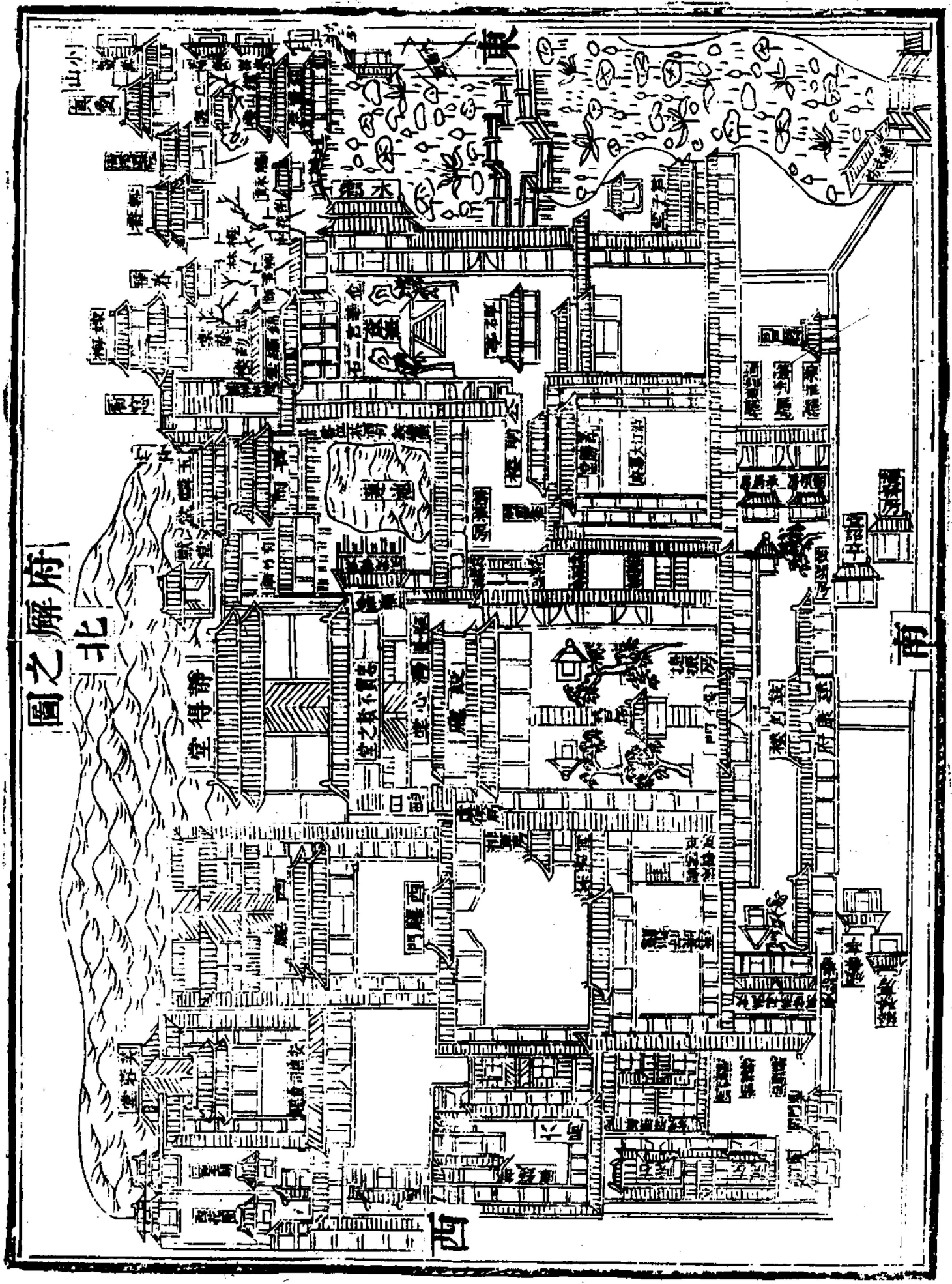


Fig. 20. A new drawing of fuxie of Jiankang according to Local Chronicles of Jiankang in the years of Jingding.

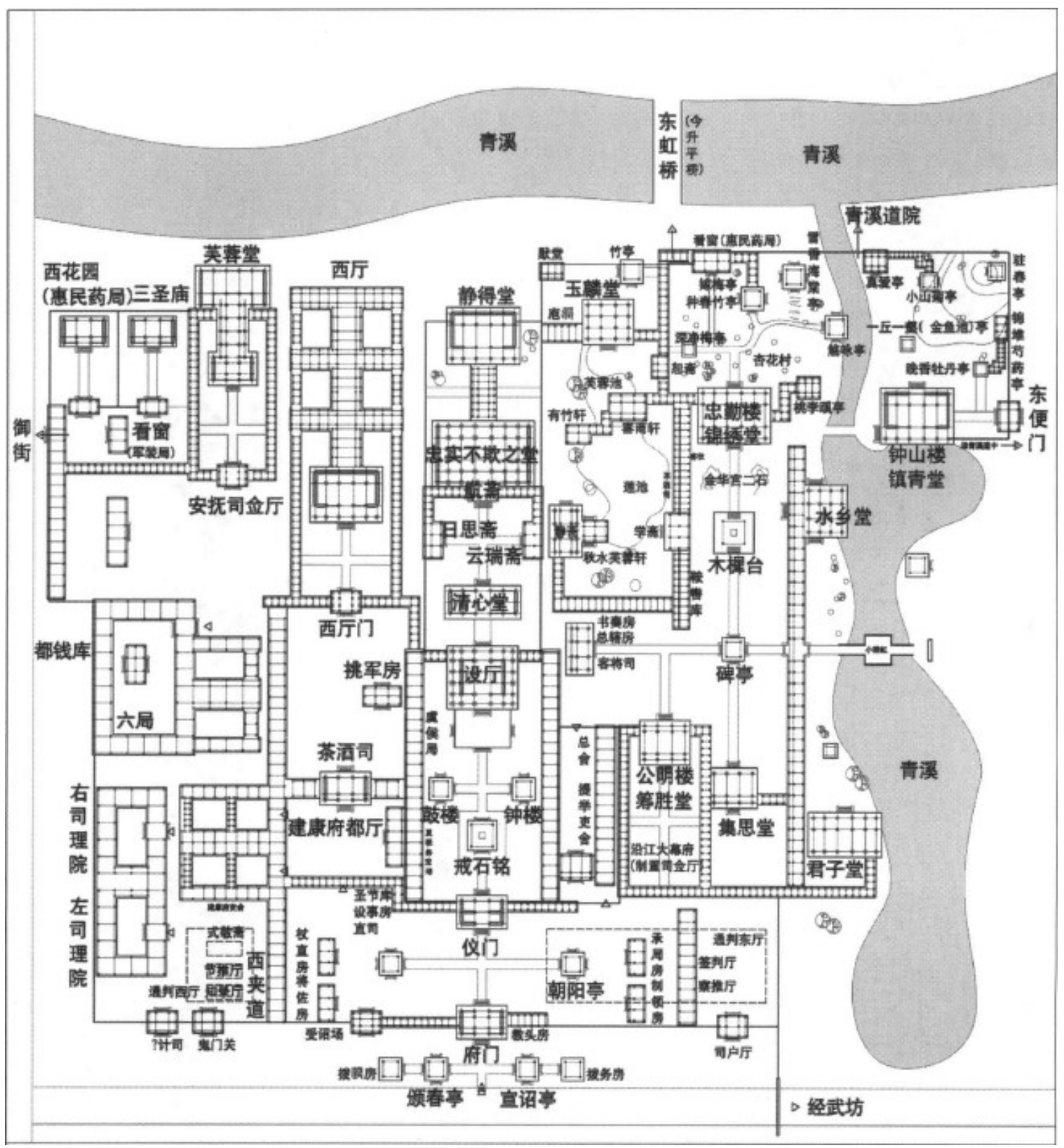


Fig. 21. The fuxie part in the engraved Map of Pingjiang.




Fig. 22. Tongyin Wanyue Tu.

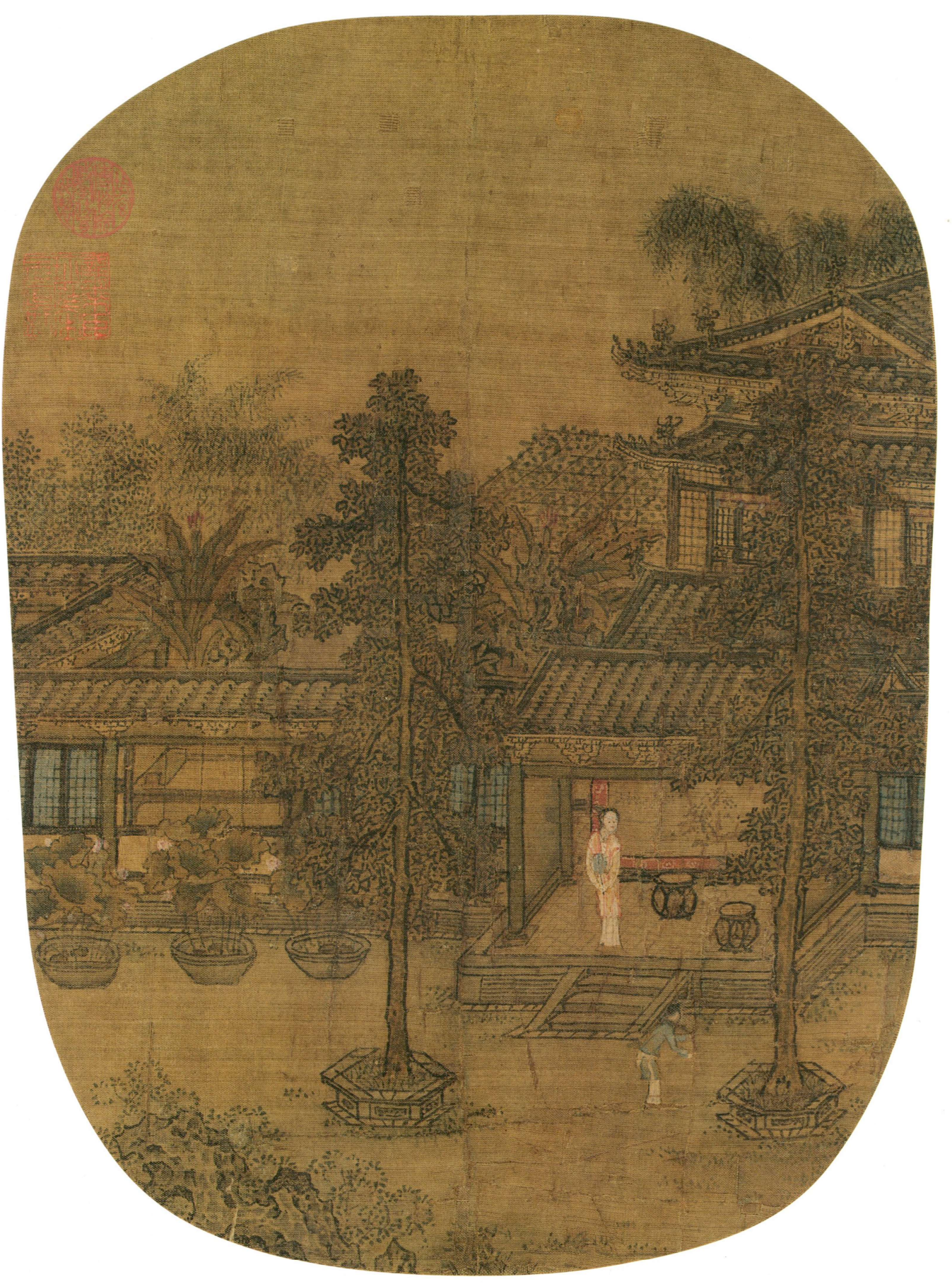


Fig. 23. An imaging plan of Fuzheng Garden.

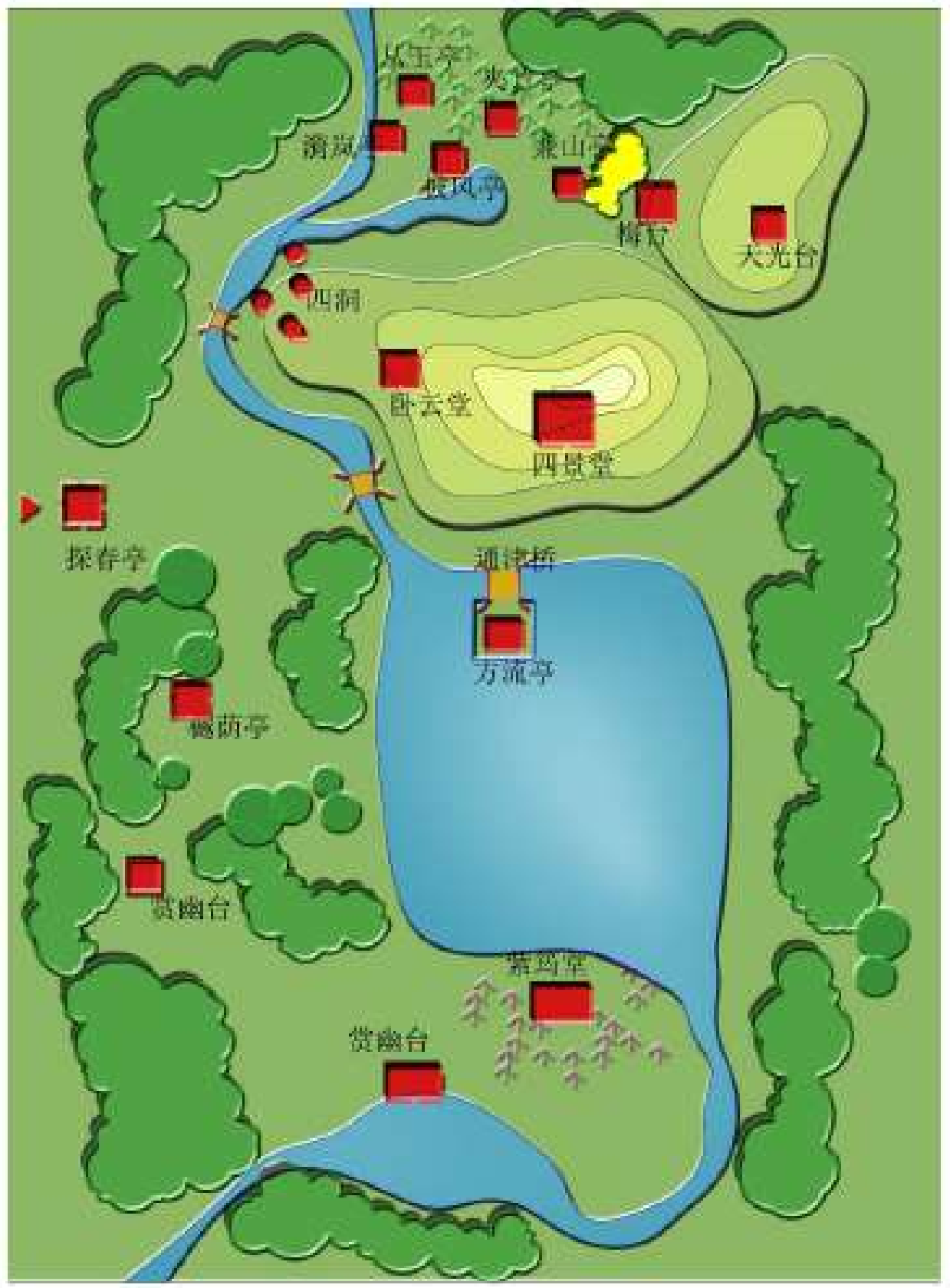


Fig. 24. A copy of Li Gonglin's Picture of Gathering in West Garden.
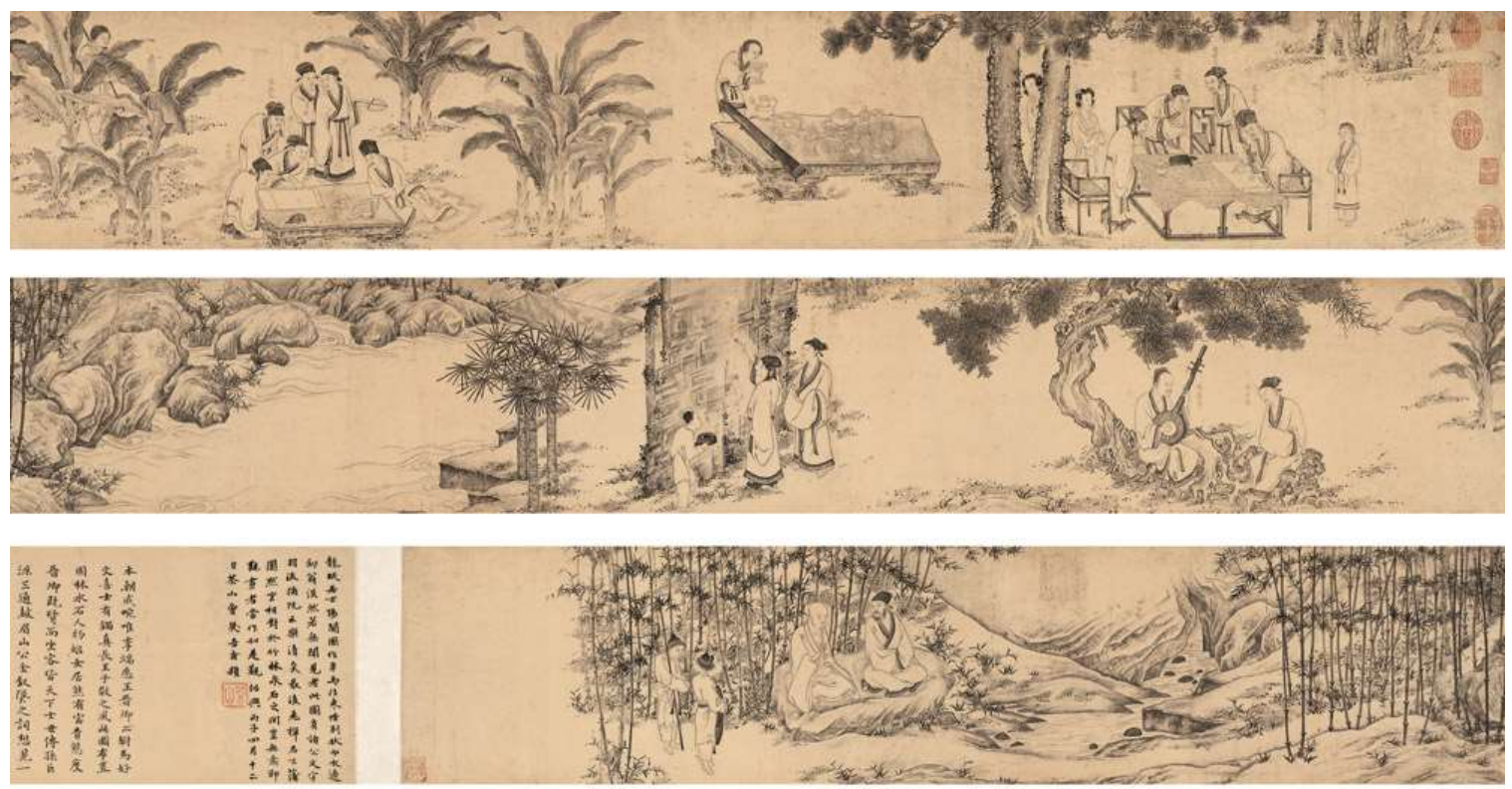

\begin{tabular}{|c|c|c|c|c|}
\hline 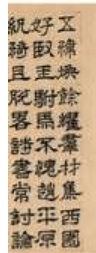 & 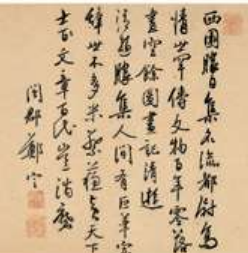 & 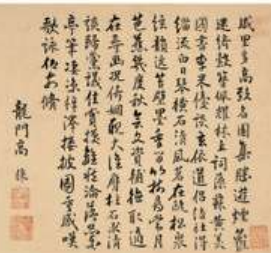 & 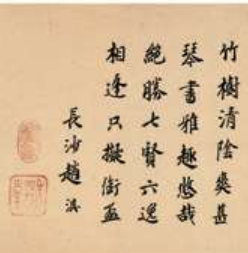 & 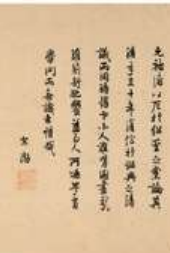 \\
\hline
\end{tabular}

\begin{tabular}{|c|c|c|c|c|}
\hline 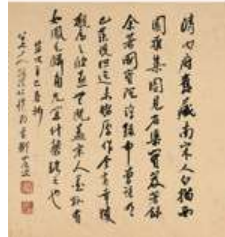 & 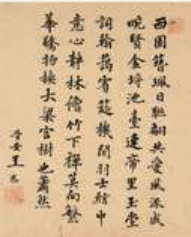 & 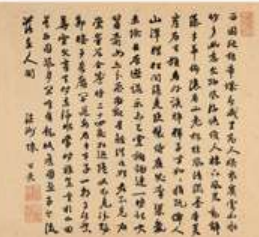 & 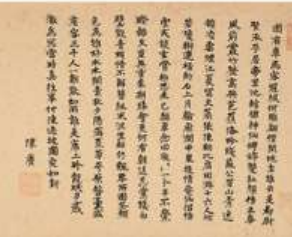 & 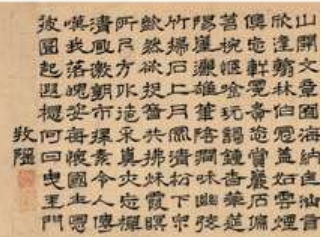 \\
\hline
\end{tabular}


Fig. 25. Imperial Garden, Jingming Pool, in Competition on the Jinming Pool.

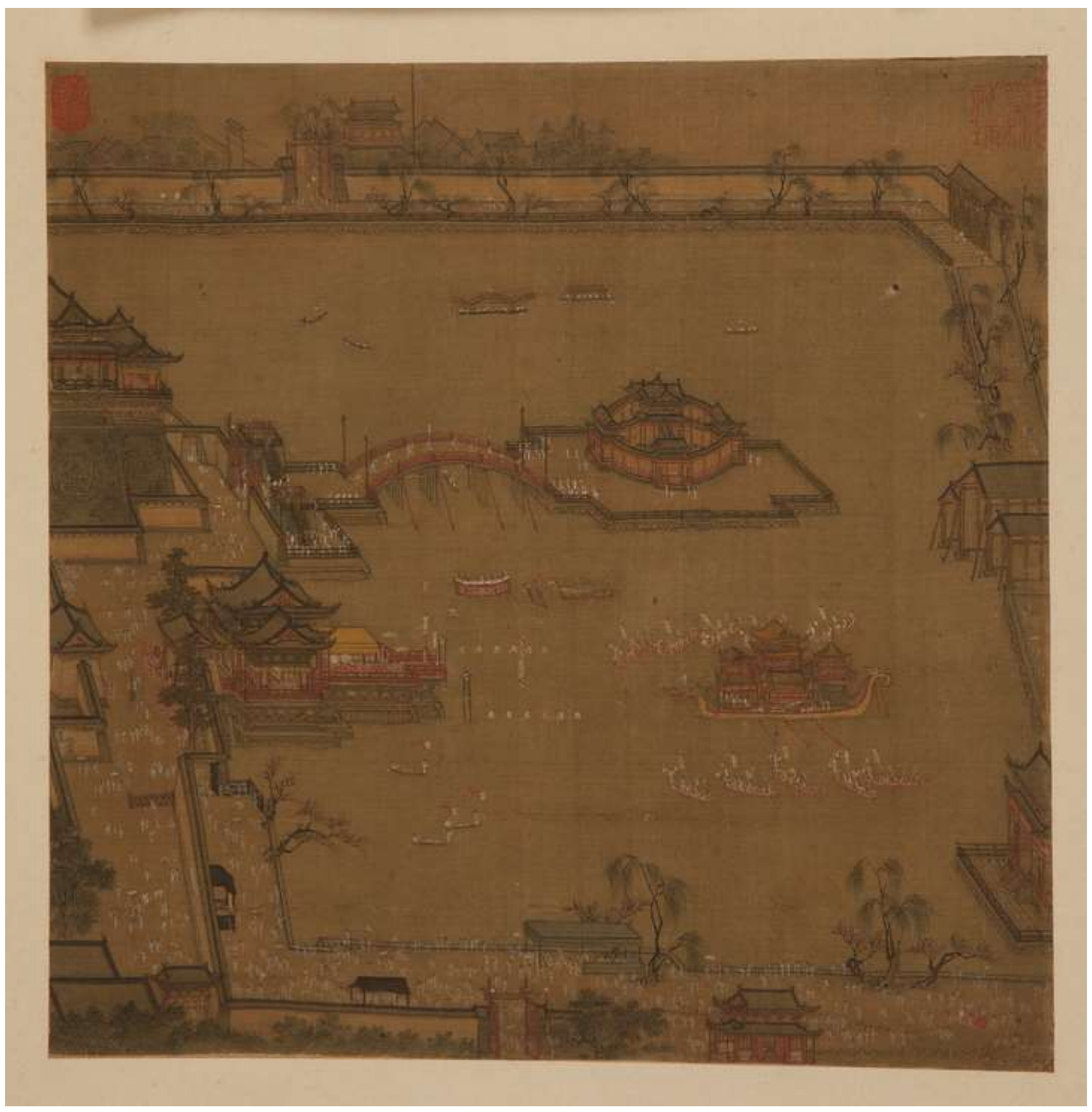




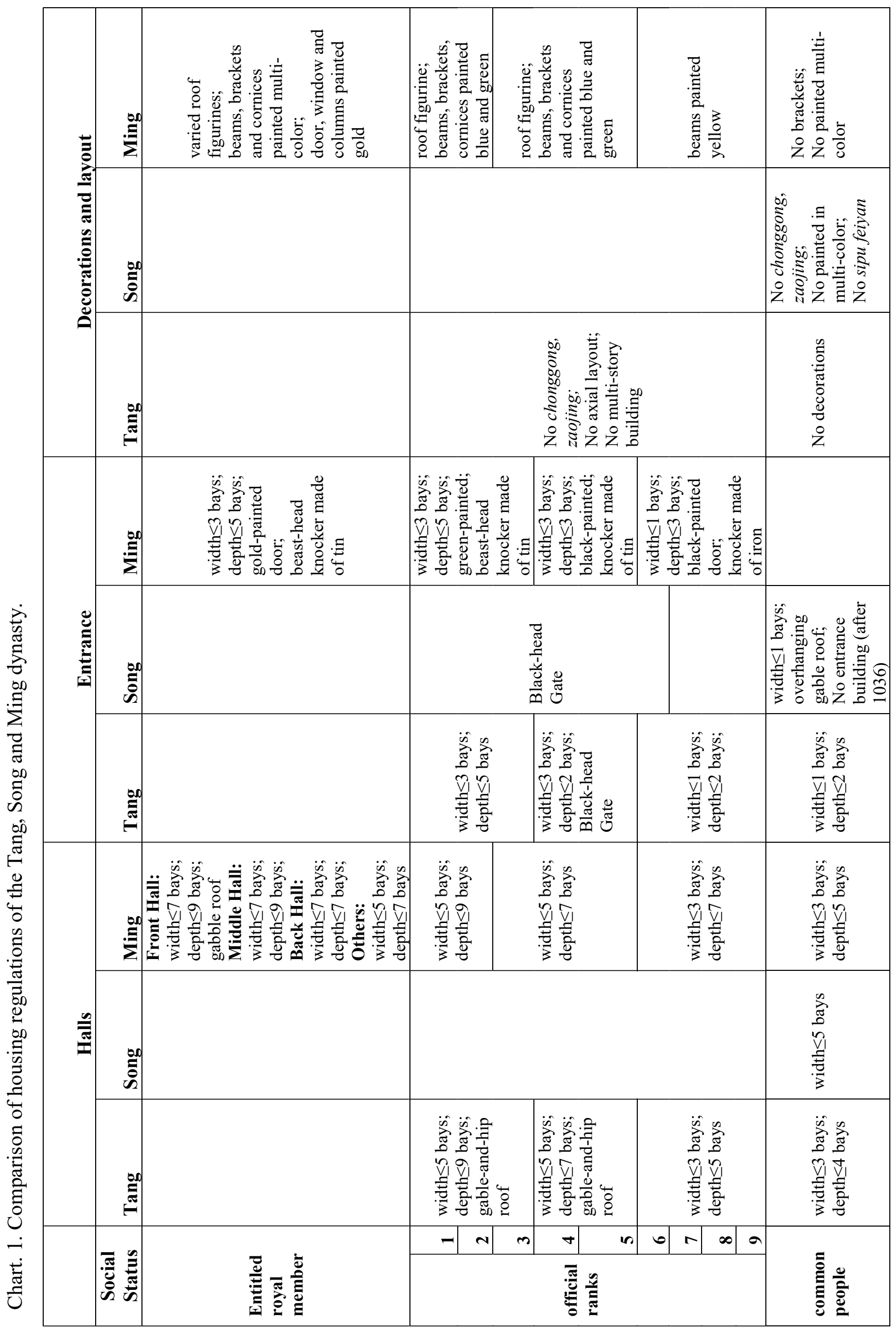

